\title{
Laboreal
}

Volume $10 \mathrm{~N}^{\circ} 1 \mid 2014$

Análise ergonómica do trabalho e formação

\section{Estratégias de trabalho e dificuldades dos professores em fim de carreira: elementos para uma abordagem sob o prisma do género}

Estrategias de trabajo y dificultades de los profesores en finalización de carrera: elementos para un enfoque bajo una perspectiva de género

Stratégies de travail et difficultés des enseignants en fin de carrière: des éléments pour une approche au prisme du genre

Teachers' work strategies and struggles towards the end of their careers: elements for a gender-oriented approach

\section{Dominique Cau-Bareille}

\section{OpenEdition}

\section{Journals}

\section{Edição electrónica}

URL: http://journals.openedition.org/laboreal/5353

DOI: 10.4000/laboreal.5353

ISSN: 1646-5237

\section{Editora}

Universidade do Porto

\section{Refêrencia eletrónica}

Dominique Cau-Bareille, « Estratégias de trabalho e dificuldades dos professores em fim de carreira: elementos para uma abordagem sob o prisma do género ", Laboreal [Online], Volume 10 NN$^{0} 1$ | 2014, posto online no dia 01 julho 2014, consultado o 07 outubro 2019. URL : http:// journals.openedition.org/laboreal/5353; DOI : 10.4000/laboreal.5353

Este documento foi criado de forma automática no dia 7 outubro 2019

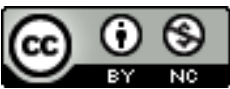

Laboreal está licenciado com uma Licença Creative Commons - Atribuição-NãoComercial 4.0 Internacional. 


\section{Estratégias de trabalho e dificuldades dos professores em fim de carreira: elementos para uma abordagem sob o prisma do género}

Estrategias de trabajo y dificultades de los profesores en finalización de carrera: elementos para un enfoque bajo una perspectiva de género

Stratégies de travail et difficultés des enseignants en fin de carrière: des éléments pour une approche au prisme du genre

Teachers' work strategies and struggles towards the end of their careers: elements for a gender-oriented approach

Dominique Cau-Bareille

\section{NOTA DO EDITOR}

http://dx.doi.org/10.15667/laborealx0114dc

Manuscrito recebido em: novembro/2013

Aceite após peritagem: maio/2014

\section{Introdução}

1 Este artigo propõe-se a abordar, tendo como referência a ergonomia centrada na atividade de trabalho dos assalariados, os problemas específicos enfrentados por professores em fim de carreira, com o intuito de perceber as motivações que estão na origem das saídas antecipadas. Com base numa pesquisa realizada em 2008-2009, cofinanciada pelo Conseil d'Orientation des Retraites (COR) - Conselho de Orientaçao das Reformas - e pelo Centre de Recherches sur l'Age et les Populations au Travail 
(CREAPT) - Centro de Investigação sobre Idade e Populações no Trabalho, tendo como objetivo compreender como é que os professores com mais de 50 anos investem nesta fase da sua carreira, quais as dificuldades específicas encontradas nesta fase do seu percurso profissional, as estratégias que constroem para tentar permanecer no ativo, dentro e fora do trabalho, e em função de que fatores se elaboram as decisões de saída precoce da profissão (Cau-Bareille, 2009).

\subsection{A questão de se levar em conta o problema do envelhecimento em França}

2 A França, como muitos países europeus, enfrenta o envelhecimento da sua população. 0 contínuo aumento da longevidade, o envelhecimento dos baby boomers e o abrandar do crescimento demográfico aparecem como ameaças para o equilíbrio financeiro dos sistemas de proteção social e dos regimes de pensões. Neste contexto, a manutenção do emprego dos seniores é uma questão importante, tanto por parte dos poderes públicos que procuram reduzir os deficits das pensões como do ponto de vista da gestão dos recursos humanos. Seguindo as recomendações de várias organizações internacionais, como a OCDE ou a Comissão Europeia, uma lógica de envelhecimento ativo substituiu a lógica da redução precoce da vida profissional através de medidas de pré-reforma (Jolivet \& Lee, 2004). Na França, isto resultou num aumento pelo Estado dos anos de descontos necessários para se ter direito à reforma completa.

Os professores/as não são exceção a esta medida. Esquematicamente, os que trabalham no primeiro grau (Pré-Escola e Elementar: alunos com idades entre 3 a 5 anos, e de 6 a 10 anos), viram a idade legal de reforma passar gradualmente dos 57 para os 60 anos. Os professores do segundo grau (Colégio e Liceu: alunos com idades de 11 a 14 anos e de 15 a 18 anos), viram a idade de reforma passar de 60 para 62,5 anos. Se deixarem de trabalhar antes de atingir esta idade, estão sujeitos a um desconto no cálculo das suas reformas em função dos meses que faltam. Apesar desta medida dissuasiva, 25\% dos professores optam pela reforma antecipada, especialmente os do primeiro grau.

\subsection{As pirâmides populacionais tornam urgentes as reflexões sobre os fins de carreira}

4 Se considerarmos o conjunto da população docente de francês no $1^{\circ}$ e $2^{\circ}$ grau, torna-se clara uma constatação. Esta é uma população cada vez mais envelhecida (ver Fig. 1): a proporção de seniores aumenta enquanto a dos jovens permanece estável. 
Figura 1: Evolução da pirâmide etária dos professores em França de 1990 a 2002

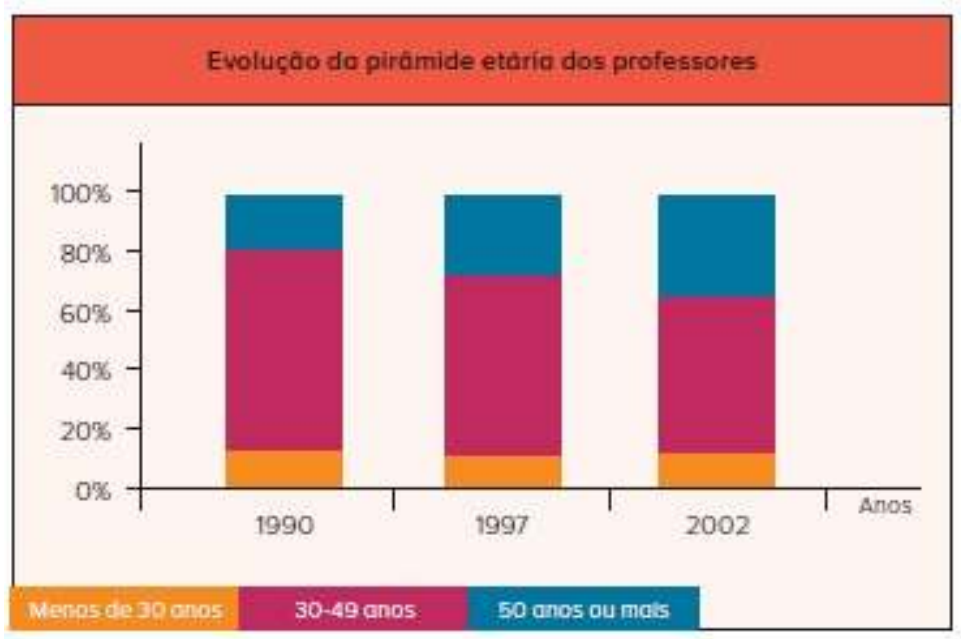

Figura 1: Evoluçä́o da pirâmide etária dos professores em França de 1990 a 2002. (Fonte: inquérito ao Emprego INSEE; tratamento DARES).

Fonte: Inquérito ao Emprego INSEE; tratamento DARES)

Cruzando as variáveis 'idade' e 'sexo' (Cf. Fig. 2-3-4), dois fenómenos destacam-se claramente:

- os coortes acima dos 50 anos são numerosos: $21 \%$ no primeiro grau e $32 \%$ no segundo grau. $\mathrm{E}$ devem aumentar nos próximos anos, se se ajustar a pirâmide etária em dez anos;

- Maior presença das mulheres nestes níveis escolares. A percentagem é mais elevada nas que trabalham com crianças muito jovens (91\% na Pré-Escola - 83\% no Elementar - 57\% no 2ㅇ grau). Esta situação deve-se aos estereótipos existentes sobre qualidades maternais supostamente intrínsecas - das mulheres.

- No secundário (colégios - liceus), enquanto as mulheres são estatisticamente mais numerosas no ensino do que os homens (57\%), são mais frequentemente certificadas [ $\left.{ }^{1}\right]$ e, portanto, menos diplomadas do que os homens para exercer a mesma profissão: há mais homens agregados [2] do que as mulheres, embora, do ponto de vista da força de trabalho em geral, eles sejam menos numerosos. 
Figura 2: Distribuição por idade e sexo dos professores do ensino do primeiro grau público em 2012-2013 [níveis Pré-Escolar e Elementar]

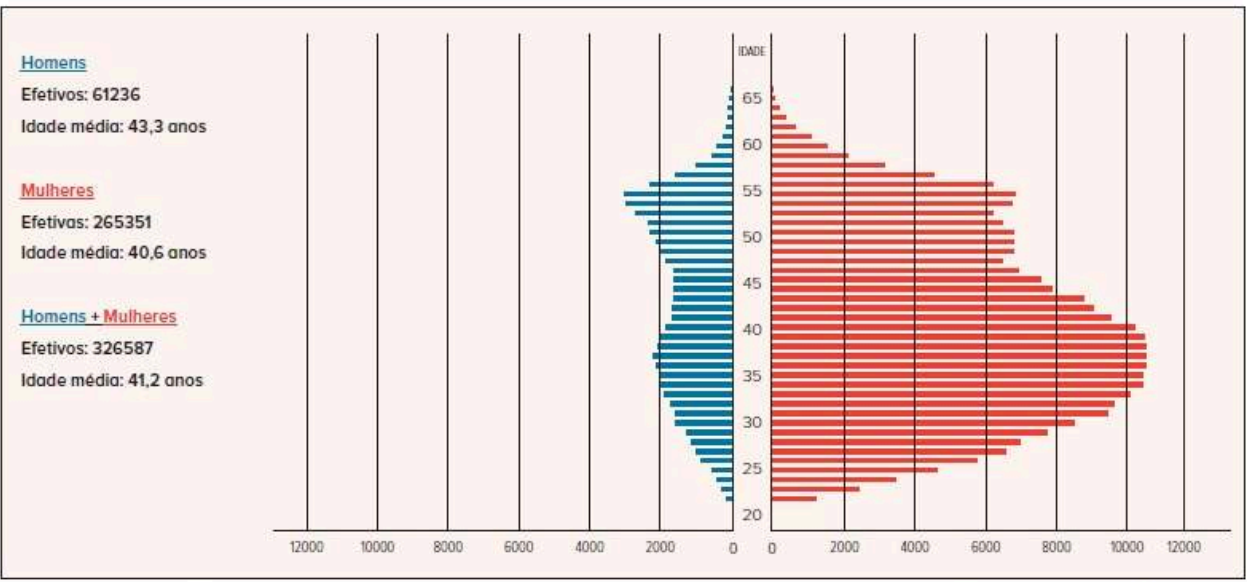

Figura. 2: Distribulçao por idade e sexo dos professores do ensino do primeiro grau público em 2012-2013 [niveis Pré-Escolar e Elementar] (Fonte: MEN-DEPP 2013)

(Fonte: MEN-DEPP 2013)

Figura 3: Distribuição por idade e sexo dos professores certificados do $2^{\circ}$ grau público em 2012-2013 [níveis Colégio e Liceu]

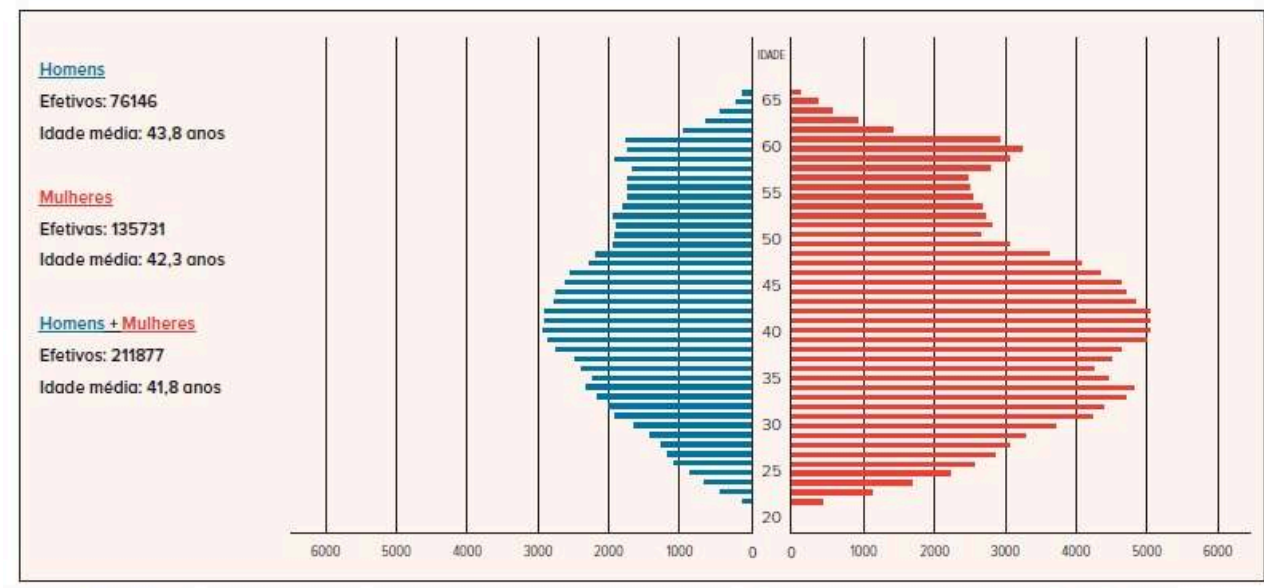

Figuro. 3: Distribuiçco por idade e sexo dos professores certificados do $2^{\circ}$ grau público em 2012-2013 [nivels Colégio e Liceu] (Fonte: MEN-DEPP 2013)

(Fonte: MEN-DEPP 2013) 
Figura 4: Distribuição por idade e sexo dos professores agregados do ensino secundário público em 2012-2013 [níveis Colégio e Liceu]

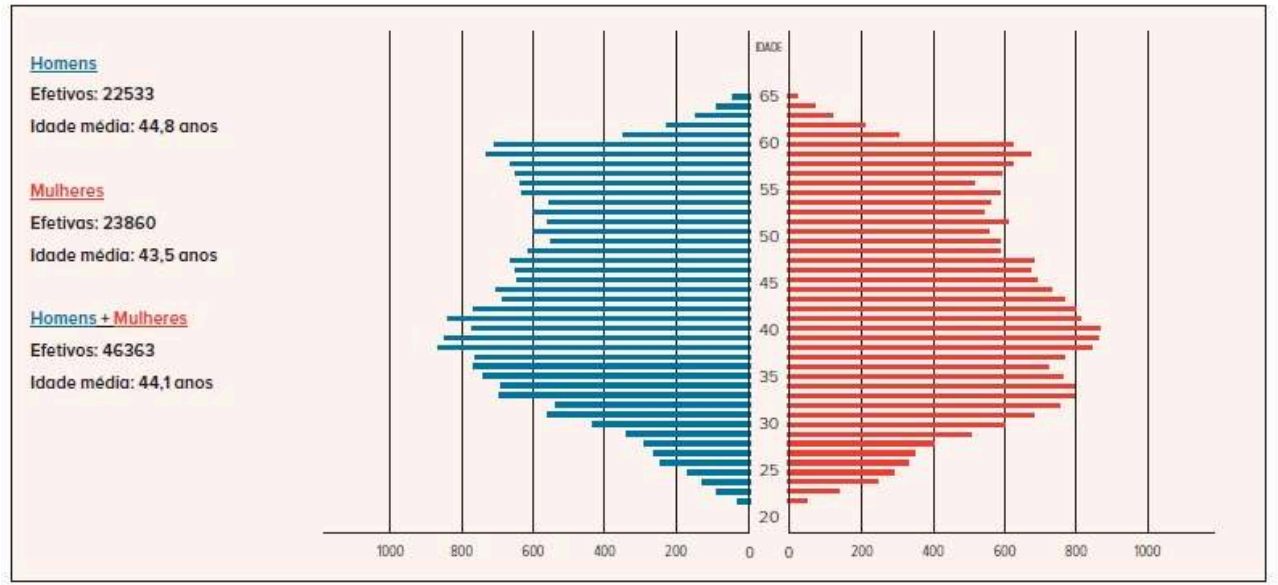

Figura 4: Distribuiçao por idade e sexo dos professores agregados do ensino secundario público em 2012-2013 [nívels Coléglo e Liceu] (Fonte: MEN-DEPP 2013).

(Fonte: MEN-DEPP 2013)

Além disso, quando foi realizado o estudo, a política de recrutamento do Ministério da Educação Nacional, do Ensino Superior e da Investigação (Educação Nacional) visava reduzir o número de funcionários, nomeadamente de professores: por cada dois que saíram, apenas um foi recrutado. Daqui surgem preocupações para os gestores de recursos humanos face às saídas precoces: como manter no emprego e com saúde os professores em fim de carreira? Os responsáveis da Educação Nacional ficam perplexos com estas saídas antecipadas para a reforma. $\mathrm{Na}$ verdade, as profissões de ensino não fazem parte daquelas consideradas mais penosas do ponto de vista dos critérios de penosidade estabelecidos pela Lei de 2010 [3] e que podem dar origem a dispositivos específicos de planeamento dos fins de carreira; as solicitações físicas, transporte de cargas pesadas, trabalho repetitivo em cadência, trabalho por turnos... são formas de penosidade referenciadas como potencialmente geradoras de desgaste prematuro. De facto, não são condições de trabalho encontradas de forma central no trabalho docente.

Isto não significa, no entanto, que estas profissões não sejam penosas. Mostramos, aliás, que as suas formas de penosidade são relativamente invisíveis se não se olhar de perto para o trabalho quotidiano, e que há urgência em revelá-las, focando as condições de trabalho, com vista a facilitar o trabalho dos mais velhos como o dos mais novos. Deste ponto de vista, os fins de carreira são reveladores das formas de penosidade no trabalho. As estratégias de regulação colocadas em prática para tentar lidar com essa situação interessam-nos como recursos adotados em função dos recursos, ora profissionais e pessoais dos assalariados, recursos que evoluem ao longo da idade e da carreira.

\subsection{As investigações sobre os fins de carreira dos professores bastante enraizadas nas áreas de psicologia e da sociologia}

8 A maioria dos estudos sobre os fins de carreira no campo do ensino são de orientação psicológica, sociológica ou médica. 
9 As abordagens psicológicas e sociológicas apresentam uma forte congruência dos resultados em torno dos fenómenos de esgotamento profissional (burnout) (Guglielmi \& Tatrow, 1998; Gursel, Sunbul \& Sari, 2002; Pillay Goddard \& Wilss, 2005; Bauer et al, 2006...) que levam os professores a criarem cada vez mais distância face à atividade, a desligarem-se progressivamente da profissão. Essa mudança no envolvimento profissional aparece relacionada com os problemas de esgotamento profissional (Burke, 1996; Schaarschmidt, 2004; Hansez, Bertrand, De Keyser \& Pérée, 2005; Jaoul, Kovess \& FSP-MGEN, 2006; CSEE, 2011), de não-envolvimento (Vandenberghe \& Huberman, 1999; Lantheaume \& Hélon, 2008), de stress no trabalho, que podem ser as causas de saídas precoces entre os professores.

o problema do esgotamento profissional coloca-se de forma mais aguda uma vez que os professores enfrentam muitas alterações nos últimos anos, que podem causar fenómenos de desgaste (Day et al, 2006) que se pode aproximar do conceito de "desgaste organizacional", desenvolvido por Lapeyre e Thebaud (2006). Segundo estes autores, "as condições de trabalho em sentido lato desempenham um papel preponderante entre os fatores de desgaste, seja de natureza física ou psicológica. Os modos de organização e gestão atuais produzem provavelmente uma acentuação deste desgaste no trabalho " (p. 6, tradução livre). "O desgaste organizacional deve ser considerado como um fator desencadeante de dois outros tipos de desgaste (físico e psíquico), mas também como um estado de degradação da organização" (p. 8, tradução livre). Estes enfatizam a forte ligação entre as evoluções organizacionais, que podem participar na construção ou destruição da saúde física, mental, psíquica (pode-se incluir social), e o processo de desgaste profissional.

11 Do ponto de vista da relação pedagógica com os alunos, vários estudos identificam também maiores dificuldades nas relações destes com os seniores (Day et al., 2006), o que afeta o sentimento de eficácia pessoal e de mestria da atividade.

12 A falta de perspetivas profissionais também é um fator determinante: as oportunidades de evolução profissional, de mobilidades internas, são pouco numerosas. A maioria dos professores exerce esta atividade toda a sua carreira, com a sensação de não ser capaz de desenvolver as suas competências noutras profissões. A falta de oportunidade relaciona-se com o facto da Educação Nacional ser a instituição que oferece menos oportunidades de formação contínua em toda a função pública [ $\left.{ }^{4}\right]$. No entanto, quando o trabalho não permite aprender (Molinié, 2005), a proporção de pessoas que não se sentem capazes de se manter no trabalho aumenta de forma muito significativa e contribui para o desejo da saída precoce da atividade de trabalho em final de carreira.

13 Mais amplamente, muitos trabalhos particularmente focados na saúde mental dos professores concordam que há uma prevalência de transtornos mentais e sintomas psicossomáticos entre esses profissionais que os autores colocam em perspetiva com um endurecimento das condições de trabalho; problemas psíquicos que Papart (2003) identificou como mais pronunciados acima dos 50 anos. A porosidade entre a esfera profissional e outras esferas da vida, muito saliente nestas profissões, parece constituir a partir deste ponto de vista um fator agravante nos problemas de saúde dos professores (CSEE, 2011, p. 19), especialmente nos últimos anos de exercício da profissão, onde surgem conflitos entre as exigências do trabalho e as necessidades de recuperação (Cau-Bareille, 2009). Estes problemas de saúde mais pronunciados no final da carreira estão, por vezes, na origem das decisões de passagem a tempo parcial ou saídas antecipadas por razões de saúde (Papart, 2003). 
14 Vários fatores parecem, pois, participar nos desejos de saídas antecipadas entre os professores, mas a decisão de sair não parece simples de tomar (Bieri, 2002; Hansez et al., 2005). Esta decisão resulta principalmente de negociações difíceis entre, por um lado, os fatores que incitam à saída, relacionados com as mudanças na profissão que podem ferir os valores profissionais, aos fenómenos de desgaste relacionados com prática do mesmo ofício ao longo de toda uma vida de trabalho, ao olhar duro com que a sociedade vê atualmente o sistema educativo, a falta de reconhecimento do trabalho realizado e os problemas de saúde que são mais propensos com o aproximar da reforma - e - por outro lado, os fatores que incitam à permanência na atividade, como o prazer de exercer a profissão, ensinar e transmitir conhecimentos e valores aos alunos, conversar com alguns pais e colegas, e os argumentos financeiros no contexto de prolongamento das carreiras que implica trabalhar mais tempo para receber uma reforma completa.

\subsection{Três dimensões pouco aparentes: a atividade de trabalho, o sexo e a idade}

Os estudos referidos destacam pouco o problema das dificuldades no exercício da profissão no quotidiano, do que exige o trabalho em fim de carreira em termos de recursos, de ajustamentos, de questionamento sobre as estratégias de trabalho, de regulações [5] necessárias, possíveis ou impossíveis no campo do trabalho para "aguentar até à reforma". Além disso, relatam pouco sobre o custo humano do trabalho que também pode exigir ajustes nas esferas da vida fora do trabalho. Todavia, a compreensão da resistência profissional deve considerar não só o professor como um funcionário dentro do estabelecimento escolar, mas também como um ator pertencente a várias esferas sociais e interagindo dentro delas, regulador, ativo no desenvolvimento e construção da sua saúde. As expectativas e as estratégias desenvolvidas a fim de continuar a exercer a sua profissão devem, portanto, ser colocadas em perspetiva com os componentes não-escolares, direcionando o foco da reflexão para gestão das temporalidades profissionais.

16 A maioria destes estudos não levam em conta, na sua reflexão, a dimensão de género, que nos parece importante para discutir o fim das carreiras. Hansez e colaboradores (2005) são os únicos investigadores que têm analisado os seus dados do ponto de vista do género; constataram que as mulheres referem mais fatores pessoais como fundamento para a saída para a reforma antecipada, concluindo assim que os determinantes familiares são centrais para a tomada de decisão. Se esta análise pelo ponto de vista do género é interessante, é de lamentar que os autores tenham limitado as suas investigações ao problema do stress, deixando na sombra problemas de saúde maiores, as margens de manobra na atividade e a evolução das estratégias de trabalho para incorporar as alterações relacionadas com a idade.

17 De facto, embora os modelos sociais tenham evoluído, as mulheres estão ainda hoje muito mais envolvidas na esfera doméstica do que os homens. Alguns estudos recentes mostram que as tarefas diárias, o cuidar dos filhos, o cuidar de idosos, são tarefas asseguradas mais por mulheres do que por homens, apesar da prática comum de uma ocupação profissional pelas mesmas (Cacouault-Bitaud, 2003; Ponthieux \& Schreiber, 2006; Jarty, 2009). Esta situação parece trazer várias consequências, que se articulam e reforçam: um trabalho de articulação das diferentes esferas da vida mais intenso para 
as mulheres do que para os homens, dificuldades em aguentar todas as esferas e a impressão de estar a "fazer tudo mal" que é geradora de insatisfação a curto e a longo prazo, um sentimento de estar despedaçado - fonte de esgotamento, uma sobrecarga global de trabalho e um alto nível de stress. Para retomar Messing e Östlin (2006), as mulheres dedicam grande parte do seu tempo e da sua criatividade a resolver esse tipo de conflito que opõe trabalho e família. Conflitos que, além disso, afetam a saúde e a serenidade de mães e crianças. Compromissos estes frequentemente fonte de insatisfação, de tensão, de culpa, de sofrimento. Acreditamos que esse posicionamento pode ter consequências a curto prazo, mas pode também estar na origem de desgaste prematuro no fim da carreira.

Os nossos trabalhos de investigação sobre o envelhecimento no trabalho inscrevem-se, portanto, nesta dupla perspetiva, do envelhecer pelo trabalho em relação às mudanças nas condições de trabalho ao longo do tempo e do envelhecer no trabalho, numa aceção alargada que implica abrir a análise aos acontecimentos fora do trabalho. Isto requer ter-se em conta a dimensão do género na análise.

\section{A investigação sobre os professores em fim de carreira: estratégias de trabalho e dificuldades}

\subsection{Objetivo e abordagem}

19 Trabalhar sobre os fins de carreira na área da ergonomia impõe conduzir, por um lado, uma reflexão sobre as condições de trabalho em função das evoluções no centro da profissão, as pedagogias, as relações quer com os pais quer com os alunos, a dimensão coletiva do trabalho, a carga de trabalho, e, por outro lado, analisar as estratégias implementadas na atividade de trabalho.

20 Também exige abordar a penosidade "sentida" pelos trabalhadores, o que inclui tanto o vivido da severidade dos constrangimentos do trabalho, os elementos relacionados com a saúde que permitem ou não fazer face aos constrangimentos da profissão, assim como o que está em jogo na atividade de trabalho em conexão com as margens de regulação possíveis ou impossíveis. "A atividade de trabalho é a elaboração sempre provisória do compromisso entre as metas de produção, as competências de que dispõe a pessoa, o desejo de preservar a saúde" (Molinié, 2012, p. 328, tradução livre). Estes são os compromissos que tentamos destacar na nossa análise.

Abordar os dilemas do fim de carreira requer ainda um interesse pelo equilíbrio procurado entre as diferentes esferas da vida, porque a atividade de trabalho é parte de um sistema de atividades global onde se articulam regulações. Como explica Curie (2002, p. 23, tradução livre), se quisermos compreender as formas de envolvimento, devemos olhar para "o que acontece nos domínios não profissionais dos indivíduos". A partir deste ponto de vista, a nossa abordagem pelo género é suscetível de revelar elementos interessantes, diferenciadores entre professores homens e mulheres; estando estas envolvidas de forma muito diferente na esfera familiar, o custo da atividade de articulação das esferas de vida é mais importante para as mulheres que para os homens, como já mencionado acima. 


\subsection{Metodologia: entrevistas individuais, grupos de trabalho- validação, comité de acompanhamento}

Depois de uma fase preliminar de revisão da literatura e pré-inquérito, optámos, nesta fase da investigação exploratória como relatada neste artigo, por entrevistas aprofundadas. Não dispondo de uma linha de base para a avaliação da evolução das estratégias de trabalho ao longo dos anos, este modo de investigação permitiu-nos abordar as arbitragens e as dificuldades sentidas na atividade, especificamente em fim de carreira. Como Brunet (1990, citado por Leplat, 2000, p. 83, tradução livre), pensamos que pode ser interessante partir da seguinte questão: "Aquilo que fazemos revela o que pensamos, sentimos ou acreditamos?". Tivemos a ideia de que os ajustamentos desenvolvidos na atividade, mas também fora do trabalho, não são, necessariamente, sempre visíveis, e que só entrevistas permitiriam aceder a esses aspetos. Os elementos recolhidos poderão permitir mais tarde que se elabore um projeto de investigação mais clássico em ergonomia, fundado nas análises da atividade nas situações de trabalho confrontadas com os dados das entrevistas.

Assim, foram realizadas entrevistas semiestruturadas, de uma hora e meia no mínimo, a 40 professores quinquagenários (ver Quadro 1): 13 homens e 27 mulheres - (16 no primeiro grau: Pré-Escola e ensino Elementar: 3 homens e 13 mulheres; 24 no segundo grau: 10 homens e 14 mulheres) - ainda no ativo ou recém-reformados/as, voluntários e distribuídos por vários estabelecimentos escolares. Alguns trabalham em tempo integral, outros em tempo parcial, tanto em bairros favorecidos como em zonas de educação prioritária [ $\left.{ }^{6}\right]$. Os participantes foram contactados por telefone. Se a pessoa concordava em nos receber, deslocávamo-nos a sua casa.

Quadro 1: Distribuição dos entrevistados por sexo e tipo de estabelecimento de ensino

\begin{tabular}{|l|l|l|l|l|l|}
\hline Sexo & $\begin{array}{l}\text { Pré-Escola (crianças de 2 a } \\
\text { anos) }\end{array}$ & $\begin{array}{l}\text { Elementar } \\
\text { (crianças de 6-10 } \\
\text { anos) }\end{array}$ & $\begin{array}{l}\text { Segundo grau } \\
\text { Colégio-Liceu } \\
\text { (crianças de 11-18 } \\
\text { anos) }\end{array}$ & Total \\
\hline Mulheres & 8 & 5 & 14 & 27 \\
\hline Homens & 0 & 3 & 10 & 13 \\
\hline Total & 8 & 8 & 24 & 40 \\
\hline
\end{tabular}

Desenvolvemos um guião de entrevista sobre o quotidiano da atividade, sobre os modos operatórios colocados em jogo no trabalho em fim de carreira, as estratégias de gestão de sala de aula, os alunos, os pais, o relacionamento com hierarquia e também o seu estilo de vida. Procuramos explorar as dificuldades da profissão, especialmente a forma como os professores em fim de carreira lhes dão resposta, assim como as estratégias de preservação implementadas na atividade como nas outras esferas da vida. As entrevistas foram gravadas, transcritas e enviadas para os interessados, para que ficassem com um registo, e se quisessem, poderem adicionar elementos ou clarificar 
pontos importantes. Foi realizada uma análise qualitativa dos dados, sem tratamento automático do discurso.

Sendo a nossa amostra limitada, organizamos, no final desta fase do estudo, grupos de trabalho em conjugação com as organizações sindicais, a fim de validar a representatividade dos resultados bem como a relevância das nossas interpretações, e discutir as nossas recomendações com um público de professores mais alargado. As restituições permitiram-nos fortalecer a nossa análise, pois os professores presentes trouxeram testemunhos que apontam na mesma direção que os nossos resultados. Este processo de validação de dados é metodologicamente importante quando se trabalha com dados qualitativos com uma amostra pequena; temíamos um viés de seleção dos entrevistados. No total, uma centena de professores, dos quais metade não participaram nas nossas entrevistas iniciais, foram abordados nesta pesquisa.

Por fim, o estudo foi seguido por um comité de acompanhamento (dispositivo social de participação do meio de trabalho na investigação), constituído por quatro representantes do COR, o diretor do CREAPT, um psicossociólogo (Jacques Curie, supracitado) um representante do sindicato e duas pessoas responsáveis pela gestão de pessoal na Educação Nacional. O comité reuniu-se cinco vezes durante os dois anos do estudo para fornecer uma atualização sobre seu progresso, para debater os dados recolhidos, levantar novas questões para aprofundar as pesquisas, possivelmente, eventualmente partilha de reflexões e recursos entre as diferentes pessoas presentes (estatísticas, bibliográficas...). Esta construção social em torno da pesquisa é metodologicamente importante em ergonomia, pois permite uma evolução, ao longo da investigação, das representações dos atores envolvidos, mobilizar o interesse dos representantes de diferentes instituições e criar uma dinâmica coletiva em torno um objeto comum, com vista a uma ação ao nível da prevenção, nomeadamente em medicina do trabalho.

\section{Resultados}

Vamos discutir primeiro, brevemente, os elementos gerais sobre as especificidades do trabalho docente, a fim de desenvolver de seguida, com mais detalhe, o que está envolvido no fim de carreira em função dos níveis de escolaridade. Para isso, vamos recorrer a alguns excertos de entrevistas, particularmente elucidantes do que foi revelado pelos protagonistas deste estudo. Quando útil, também mostramos a proporção daqueles/as que assumiram uma posição particular.

\subsection{Elementos gerais sobre a atividade docente}

Seja qual for o nível de ensino, o estudo do trabalho docente revela um trabalho "exigente, difícil", uma atividade multifuncional que implica uma mobilização física, afetiva e subjetiva permanente. Os professores/as sublinham o acumular de constrangimentos e de exigências cujos efeitos combinados podem causar fenómenos de desgaste a longo prazo, num contexto em que as margens de manobra são relativamente limitadas: "Não existe uma estratégia de evasão possível, de escapatória quando se está diante da turma" (H, 2ำ grau, 58 anos). inquéritos nacionais. Tem diferentes aspetos: o tempo de trabalho na escola que 
abrange o tempo de ensino face-a-face com os alunos, o trabalho administrativo, as reuniões com os pais, as preparações das aulas, tarefas diversas, e o tempo de trabalho em casa (preparações, incluindo correções) que pode ser muito significativo, especialmente no nível secundário por causa da extensão dos trabalhos para corrigir. Para entender as dificuldades sentidas e as estratégias de preservação implementadas em fim de carreira, é preciso integrar estas diferentes dimensões do trabalho.

Apesar de ser uma atividade que decorre dentro de estabelecimentos onde estão presentes numerosos colegas, os professores expressam todos um profundo sentimento de solidão na atividade; sozinhos como "mestres da turma" e na luta com as dificuldades. Raros são os que falam sobre as suas dificuldades pessoais com colegas por medo de revelar fraquezas; apenas se observa que ocorrem discussões sobre um ou outro aluno que cause problemas. Os professores entrevistados estimam em mais de $85 \%$ que a sua hierarquia raramente é um apoio à sua uma atividade.

31 Os professores têm, pois, o sentimento de uma invisibilidade das penosidades do trabalho e das dificuldades da profissão.

\subsection{Evoluções internas que se inscrevem nas evoluções da profissão}

Os professores entrevistados afirmam todos que o ensino francês teve muitas reformas que afetam todos os níveis de ensino e contribuem para uma densificação da sua atividade. Afetam tanto o conteúdo da educação (os currículos) como as didáticas profissionais. Damos dois exemplos.

33 As avaliações dos alunos estão a aumentar a nível nacional, incluindo ao nível da PréEscola onde a sua relevância é amplamente discutida pelos professores. $\mathrm{O}$ rápido desenvolvimento das crianças nesta idade, as modalidades de avaliação (escrita) em completo desfasamento com as modalidades de aprendizagem dos conteúdos fundamentais pelo jogo, a mobilização corporal, a oralidade, o desenho... colocam-lhes problemas. Fazer as avaliações é um processo longo e constitui uma carga de trabalho adicional e um desperdício de tempo num contexto mais geral de dificuldades para lidar, num curto espaço de tempo, com uma série de disciplinas mais importantes. Estas avaliações não são necessariamente uma ferramenta de apoio na gestão dos alunos e na remediação das suas dificuldades. Finalmente, os professores estão preocupados que estes sejam essencialmente instrumentos de controlo de sua própria atividade, visando reduzir a sua autonomia. Daqui vem a sua resistência em pô-las em prática, pois expõem-se a sanções que podem afetar a sua progressão na carreira, e portanto o cálculo da sua reforma (Cau-Bareille, 2012).

Nos colégios, mas especialmente nos liceus, os professores entrevistados apontam para o facto de que as alterações no ensino tendem a sobrecarregar os programas, o que provocou já movimentos de protesto e greves (especialmente nas disciplinas de história e economia). Sentem que a extensão dos conceitos a serem abordados faz-se em detrimento de aprofundar os conceitos de base essenciais (particularmente em matemática): os professores têm a impressão de que "sobrevoam pelas noções" ao invés de munir os alunos para a construção de raciocínios. Para estes professores em fim de carreira, é o coração da sua disciplina que é afetado. Foi isso que fez com que, num dado momento, o prazer na descoberta de uma disciplina, e a escolha de seguir esta 
profissão, ficasse enfraquecido: os professores já não se reconhecem nas modalidades de aprendizagem das suas matérias.

Assim, o fim da carreira, muitas vezes fica contaminado com amargura e dificuldades em fazer valer os seus métodos de ensino, os seus valores, a sua experiência. É o significado da sua atividade que parece ser afetado por essas mudanças. Este é um dos argumentos envolvidos na decisão das saídas antecipadas. Isto ecoa a noção acima mencionada de "desgaste organizacional", desenvolvida por Lapeyre e Thebaud (2006).

\subsection{Astreintes físicas, mentais, psicológicas que aumentam com a idade}

Com a idade, o custo da atividade de trabalho aumenta; todos os professores o afirmam. Apesar das competências construídas ao longo do tempo, estimam que os seus recursos pessoais para lidar com as exigências diminui no fim da carreira. "Temos que ir mais longe em si mesmo para encontrar a energia necessária para a atividade de trabalho" (F, $1^{\circ}$ grau, 57 anos); o termo energia refere-se aqui às noções de recursos físicos, mentais, psíquicos. Esta dificuldade acrescida em fim de carreira contribui para uma tensão global na atividade e a uma transformação na maneira de produzir a atividade.

\subsection{Aumento da fadiga física e dos problemas de saúde}

O termo "esgotamento" é mais referido em fim de carreira do que o termo "cansativo" expresso pelos professores em início de carreira, para marcar a intensidade da fadiga. Isto está relacionado tanto com a forma como o constrangimento é sentido, que evolui com a idade (o custo humano do trabalho dentro e fora do trabalho), mas também com problemas de saúde que se tornam mais presentes e mais incómodos na atividade. No pré-escolar, 7 em 8 professoras (que são todas mulheres) queixam-se de dor nas pernas, de problemas de circulação e de problemas ginecológicos. Problemas de coluna, do tipo lesões músculo-esqueléticas, são relatados em todas as entrevistas em relação à altura do plano de trabalho dos alunos, que força os professores a posturas dolorosas, o facto de pegar nas crianças ao colo para as consolar ou para as levar a alguma atividade: "O trabalho de oficinas, na Pré-Escola, é muito interessante; mas quando se passa os cinquenta anos, começamos a ter problemas de saúde devido a estarmos em pé o dia todo. Coisas muito concretas: problemas de varizes, problemas ginecológicos, de estarmos sempre de pé, isso não é saudável. Então eu pergunto-me: como é que eu vou aguentar?" (F, 1ํgrau, 52 anos). Isto explica a implementação no trabalho de estratégias de preservação para tentar limitar as dores: "Eu, agora, tenho a minha cadeira, eu tenho uma cadeira numa ponta, uma cadeira na outra, porque caso contrário eu estava cansada de estar de pé ou inclinada. Mas a verdade é que eu tenho mais e mais necessidade de estar sentada" (F, $1^{\circ}$ grau, 50 anos). A intensidade das dores e desconforto na atividade justificam em fim de carreira ter apoio médico, paramédico e a toma diária de analgésicos ( 7 em 8 professores do pré-escolar).

No liceu ou no colégio, todos os professores enfatizam um maior cansaço do que no início ou a meio da carreira, e uma dificuldade em aguentar um dia de aulas inteiro: "Sinto-me a esvaziar até ao tutano, resisto muito menos que dantes" (F, $2^{\circ}$ grau, 60 anos). Menos resistente à sucessão de aulas, no mesmo dia, os professores tentam negociar os seus horários durante a votação no final do ano para a atribuição de horários para o ano letivo seguinte. Diferentes tipos de estratégias de adaptação emergem nas entrevistas: 
alguns pedem o espaçamento das aulas pela semana, enquanto os mais jovens preferem agrupar tudo em dois ou três dias (8 em 24$)$; outros pedem para só trabalhar apenas meios-dias para minimizar a fadiga ( $3 \mathrm{em} 24)$; outros ainda procuram ter furos nos horários ao longo da jornada para se recuperar entre as aulas (2 em 24), ainda que este tipo de gestão do horário tenha sido considerado no início da sua carreira como um "mau horário" ou "uso penalizante do tempo", que justificaram pedidos de alterações ao diretor da instituição. Estas são estratégias que, entretanto, vão depender da flexibilidade do diretor do estabelecimento, da sua atenção e das suas próprias limitações na organização dos horários das turmas. A gestão dos horários torna-se uma questão de manutenção da saúde na atividade no final da carreira.

\subsection{Dificuldades na realização de determinadas atividades físicas} referem situações de forma bastante parecida. Alguns mencionam acidentes de trabalho com consequências sobre a sua atividade. De facto, eles procuram preservar os seus corpos em fim de carreira, participando menos nos exercícios, e fazendo mais observação. Os professores enfatizam sentir cada vez mais dificuldades no transporte de cargas, manutenção dos equipamentos e na preparação dos espaços. Embora o processo de cooperação entre os professores entre em ação e que eles façam mais apelo aos estudantes para disporem os materiais para utilização em aula, esta parte da atividade torna-se muito custosa. Perante isto, evidencia-se o facto de que muitas mulheres desta disciplina optam em fim de carreira por trabalhar a tempo parcial (15\% de mulheres / $6 \%$ homens), de acordo com fontes sindicais.

\subsection{Uma tensão nervosa crescente associada com a prática da profissão}

Todos os professores/as entrevistados/as evocam uma diminuição da paciência com a turma e com o comportamento de alguns alunos: "A paciência muda muito com o avanço da idade, oh sim, é claro! Eu acho que não escapa!" (F, 2º grau, 54 anos).

Seja qual for o nível de ensino, os professores estão cada vez mais intolerantes com o ruído na sala de aula, como se o seu limiar de tolerância tivesse reduzido com a idade. Este aspeto leva ao aumento da carga de trabalho mental, fator de fadiga. Suportando menos esta situação, constroem estratégias para tentar controlar, modular o ruído. Estas estratégias diferem, dependendo do nível escolar.

Laboreal, Volume 10 NN$^{\circ} 1$ | 2014 
44 No pré-escolar, o problema é agravado (8 em 8 professores): "O meu cansaço está muito relacionado com ruído. o barulho incomoda-me, eu acho... É, o facto de que é uma barulheira, uma barulheira constante. Então, eu tento encontrar um monte de pequenas coisas (momentos de cantar, contar histórias) para garantir que as crianças fazem o mínimo de ruído possível... Mas, em contrapartida, os momentos em que eles fazem menos barulho, é verdade que é graças à minha energia empregue, dispensada" (F, $1^{\circ}$ grau, 52 anos).

No colégio ou liceu, a intolerância ao ruído acentua-se com a idade, como já foi dito, mas os seus mecanismos de gestão diferem. Oito em vinte e quatro professores optam por castigos ou pela remoção temporária de alguns alunos da sala de aula, o que é muitas vezes percebido pela hierarquia como reflexo de incompetência para controlar a turma. Dois professores disseram-nos que, em fim de carreira, negoceiam mais facilmente com os alunos problemáticos aceitando que eles façam qualquer outra coisa em vez de ouvir a aula, para conseguir o silêncio: "uma estratégia insatisfatória do ponto de vista pedagógico" reconhecem, pois não estão, de todo, orgulhosos, mas isto permite-lhes conseguir um ambiente de trabalho mais tranquilo.

Essas tensões, este stress que os professores manifestam como mais intensos no fim da carreira, fazem-se sentir não só no trabalho, mas também, e cada vez mais, em outras esferas da vida, na relação com a família (referido por 16 em 40 participantes). Estas tensões traduzem-se às vezes em distúrbios infra patológicos particularmente nas mulheres (enxaquecas, dores, ...), problemas de sono que justificam consultas médicas especializadas ou medicamentos (8 em 27 mulheres). Esta situação está na origem das preocupações relativamente à capacidade de continuar a exercer a profissão.

\subsection{As dificuldades de recuperação que se acentuam}

o fim da carreira é acompanhado por uma recuperação cada vez mais difícil depois de um dia de trabalho, de uma semana, dos trimestres, havendo uma maior necessidade de dividir a vida de trabalho e vida pessoal (20 em 40). Uma recusa marcada em aceitar trabalhar em casa à noite (15 em 40) ou aos fins-de-semana, a fim de criar tempo para si mesmo, para se recuperar. Distanciar-se das condições de trabalho como estratégia para a preservação e condição para "aguentar até à reforma" pode ser associado a uma forma progressiva de intolerância, com a idade, da intrusão da vida de trabalho na esfera privada. Este é um dos motivos da transição para o trabalho a tempo parcial entre as mulheres.

\subsection{Uma fadiga mais acentuada nas mulheres em fim de carreira}

Nas nossas entrevistas, surgiram elementos relacionados com a dimensão do género. As mulheres parecem sentir uma fadiga mais intensa do que os homens em fim de carreira, que pode estar ligada a dois fatores: a menopausa e o acumular de atividades profissionais e de gestão da família ao longo de toda a vida profissional.

O impacto da menopausa na atividade de trabalho e na fadiga foi evocado espontaneamente pela maioria das professoras de pré-escolar (6 em 8 professores). A menopausa, que ocorre frequentemente perto dos 50 anos, é, com efeito, uma fase de desequilíbrio do organismo com efeitos físicos e psicológicos que podem afetar a vida profissional como a vida em geral, e que requer ajustes delicados. A menopausa desperta um sentimento de impotência para lutar contra a fadiga, para a ultrapassar, 
apesar do seu saber-fazer e da sua experiência profissional: "Tinha 47 anos quando tive a menopausa. Assim, a partir daí, fadiga, uma grande fadiga! E a sensação de simplesmente não... Às vezes digo a mim mesma que a Pré-Escola é demais para mim!" (F, $1^{\circ}$ grau, 53 anos). Os professores concedem de início pouca atenção a esta fadiga que vai começando lentamente, mas que se faz cada vez mais presente e penalizadora na sua atividade de trabalho: "Era cada vez mais difícil aguentar um dia inteiro" (F, $1^{\circ}$ grau, 56 anos). Em seguida, surge a culpa que reforça o seu mal-estar no fim da carreira, advindo um acréscimo de gasto de energia numa tentativa de compensar o que não são já capazes de controlar, esforços que vão aumentar a fadiga já instalada. Um sentimento, finalmente, de estar nos limites do que podem fazer, gerador de verdadeiras preocupações em relação aos últimos anos de atividade: "Eu calculei que me restam 3 anos. Agora estou preocupada porque eu acho que se eu estou assim agora, será que eu vou aguentar três anos? Porque é difícil, porque é pesado. Eu bem vejo que a cada ano, se tanto, eu tenho mais qualquer coisa! É como subir uma escada: tenho mais um degrau a subir ao nível da fadiga. Digo a mim mesma que eu nunca vou conseguir, o quê!"' (F, 1ํo grau, 54 anos).

50 A combinação das atividades profissionais e da gestão da família também foi uma questão citada como uma fonte de desgaste precoce por $2 \mathrm{em} 13$ mulheres entrevistadas no primeiro grau (Pré-Escola e Elementar). "Aos 30 anos, eu lutava para aguentar ao mesmo tempo as exigências do trabalho e os constrangimentos da vida familiar. Eu tive anos difíceis com três filhas que tinham pouca diferença de idade. É possivel que eu tenha saturado num determinado momento e o cansaço que eu sentia aos 45 anos esteja relacionada com esse período. Estava saturada em 45 anos por coisas antigas" (F, $1^{\circ}$ grau, 50 anos). Aqui se apontam os conflitos que mais especificamente as mulheres precisam de gerir entre os diferentes papéis sociais que devem assumir e tentam articular.

\subsection{Estratégias para gerir as dificuldades associados à idade na atividade}

51 Os assalariados não são passivos em relação aos vários processos de transformação.

52 No pré-escolar, as professoras tentam limitar a carga de trabalho escolhendo o seu nível de ensino, citando a sua antiguidade na escola para fazer valer os seus desejos perante os colegas. Muitas vezes optam, em fim de carreira, pelos grupos dos "grandes" (7 em 8), isto é, crianças mais velhas, que têm menos necessidade de serem pegadas ao colo e que já iniciaram as regras de escolarização; só uma docente escolheu os mais novos, para poder fazer a sesta com as crianças e recuperar da fadiga, que está cada vez mais presente. Do ponto de vista do trabalho na sala de aula, as professoras desenvolvem várias estratégias para limitar o esforço físico, o ruído, entrar em situações críticas. Investem menos nos exercícios físicos de psicomotricidade, de dança (7 em 8): usam mais o "fazer fazer" com os alunos. São menos propensas a organizar visitas de estudo com os alunos ou aulas verdes [7] fora da escola, muito apreciadas pelos alunos (6 em 8): o custo de organizar estas aulas muitas vezes dissuade de os levar avante. Porém, estas estratégias não são suficientes para compensar os efeitos da idade.

Todos os professores deste nível fazem modificações nas outras esferas da vida para "aguentar a sua atividade de trabalho até ao fim da carreira". Muitos optaram por abandonar as suas responsabilidades em associações (6 em 8), por uma redistribuição das responsabilidades familiares entre o casal (6 em 8), por uma reorientação do seu trabalho, visto cada vez mais como custoso e requerendo um maior tempo de 
recuperação. Mas estas estratégias podem ser insuficientes para algumas das professores, daí a mudança para o tempo parcial como uma "estratégia de sobrevivência" para continuar o seu trabalho e "manter o prazer de trabalhar" (2 em 8) e, às vezes, as decisões de pedir a reforma antecipada (1 em 8).

Nas escolas secundárias, as margens de manobra são mais significativas porque o tempo de presença com os alunos é mais reduzido ( $18 \mathrm{~h}$ ou $15 \mathrm{~h}$, dependendo da qualificação [ ${ }^{8}$ ] em vez de $24 \mathrm{~h}$ no primeiro grau), e os professores intervêm em várias turmas. As entrevistas revelam regulações muito discretas e não socializadas no seio dos estabelecimentos escolares. Por exemplo, em fim de carreira, 14 em 24 dos professores entrevistados recusam ser diretor de turma, que é uma responsabilidade a acrescer ao seu tempo de ensino e que é fonte de remuneração e de reconhecimento tanto pelo estabelecimento como por parte dos pais. Isto permite-lhes encontrar tempo pessoal. Durante o processo de alocação nas turmas para o ano seguinte, os professores pedem para limitar o número de níveis de turmas em que atuam, a fim de reduzir o tempo de preparação e correção, sendo a antiguidade no estabelecimento um critério importante para negociar esta alocação nas turmas de um ano letivo para o seguinte. Estes profissionais evitam ter 6 horas de aulas seguidas no mesmo dia (15 em 24), devido a ser mais difícil gerir a fadiga. Propõem-se mais espontaneamente para trabalhar nas turmas que incluem crianças com dificuldades de aprendizagem (6 em 24), pois têm uma carga aligeirada e mais tempo de trabalho com os alunos, o que, por consequência, limita o número de turmas em que intervêm. Recusam-se mais sistematicamente fazer horas extraordinárias (18 em 24), chegando até a optar por obter um horário a tempo parcial para evitar estas horas extra (7 em 24). Apenas 3 professores com menos de 57 anos (dois homens e uma mulher) aceitaram fazer horas extraordinárias, e têm, respetivamente 51 e 52 anos: são jovens quinquagenários. Do ponto de vista da atividade coletiva, dizem-se mais relutantes em colaborar com colegas (10 em 24), a elaborar projetos interdisciplinares que são grandes consumidores de coordenação e, portanto, de tempo. Nota-se, também, uma reorientação no que acontece nas salas de aula. Acontece ainda que, durante a carreira, alguns professores desenvolveram, para além do seu trabalho de "base", uma atividade de ensino fora do estabelecimento, muitas vezes orientada para o público adulto (formação contínua, cursos em universidades) (8 participantes, maioritariamente homens); essas aulas suplementares são consideradas "espaços de respiração" e de desenvolvimento pessoal. Devido ao aumento do custo da atividade e à necessidade de reequilibrar a sua carga de trabalho em fim de carreira, muitas vezes os professores resignam-se a não as manter; renúncia que nem sempre é fácil. Estas estratégias encontram-se tanto nos homens como nas mulheres.

55 As possibilidades de regulação dentro dos estabelecimentos escolares não são, portanto, as mesmas em função do sexo, dos professores e dos níveis de ensino; são menos importantes no nível primário do que no secundário. Esta é também uma razão pela qual há mais saídas antecipadas e horários a tempo parcial no primeiro grau do que no segundo. Continuar a exercer a sua atividade de trabalho até ao fim da carreira irá influenciar gradualmente, mas em profundidade, o estilo de vida dos professores, tanto no trabalho como fora dele, os equilíbrios que se estabelecem entre as esferas de vida. É em torno desta avaliação cognitiva das necessidades e das possibilidades de reajustes da atividade nas diferentes esferas da vida que se vão tomar as decisões de saída antecipada: muita renúncia, desequilíbrios, reconfigurações que podem levar a um sentimento de não conseguir realizar o seu trabalho com saúde. E as arbitragens em 
termos de escolha de sair ou permanecer integram esta dimensão do estilo de vida: até onde se está disposto a reconfigurar o estilo de vida para aguentar o trabalho?

\section{Discussão}

A análise das entrevistas revelou as especificidades do trabalho docente em função dos níveis de ensino e das disciplinas. Se certas formas de sofrimento são relativamente comuns, outras são mais específicas, estando relacionadas com as formas de organização do trabalho, com as margens de manobra possíveis nos estabelecimentos e fortemente dependentes dos diretores das escolas no secundário. Tentámos resumir e colocar em paralelo na Tabela 2 os principais problemas encontrados em função dos níveis escolares e das regulações praticadas no campo do trabalho e na esfera privada.

Tabela 2: Síntese dos diferentes tipos de dificuldades encontradas e dos modos de regulação no trabalho e fora do trabalho mencionados pelos professores em fim de carreira do nosso estudo

\begin{tabular}{|c|c|c|c|}
\hline & $\begin{array}{l}\text { Problemas encontrados } \\
\text { em fim de carreira }\end{array}$ & $\begin{array}{l}\text { Regulações possíveis } \\
\text { no domínio do trabalho }\end{array}$ & $\begin{array}{l}\text { Regulações nas outras } \\
\text { esferas da vida }\end{array}$ \\
\hline $\begin{array}{l}\text { Pré-Escolar } \\
\text { (Mulheres) }\end{array}$ & $\begin{array}{l}\text { Sensação de esgotamento } \\
\text { Sentimento de ter menos } \\
\text { recursos para fazer face à } \\
\text { atividade } \\
\text { Penosidade vivida mais } \\
\text { significativa quando os } \\
\text { exercícios implicam o } \\
\text { envolvimento do corpo } \\
\text { Maior sensibilidade ao ruído } \\
\text { Maior tensão nervosa, menos } \\
\text { paciência para os alunos } \\
\text { Problemas de recuperação } \\
\text { Problemas de saúde } \\
\text { geradores de dores na } \\
\text { atividade (costas, varizes) } \\
\text { Cada vez mais dissonâncias / } \\
\text { evolução da profissão } \\
\text { Maior intolerância à intrusão } \\
\text { na vida fora do trabalho }\end{array}$ & 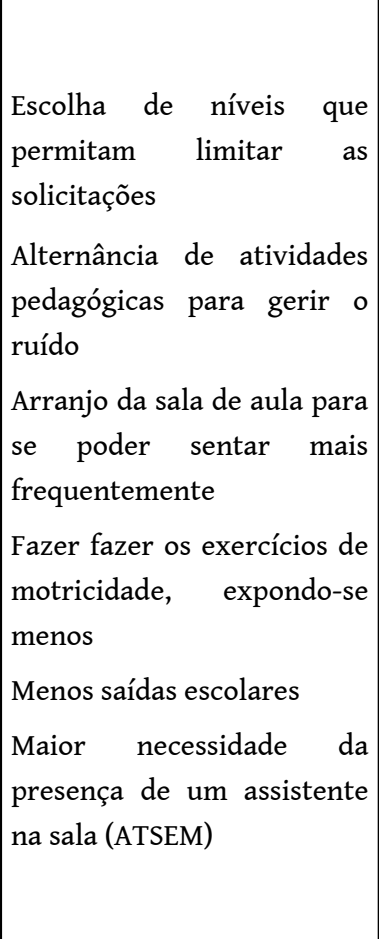 & $\begin{array}{l}\text { Prática de atividades } \\
\text { recuperadoras, } \\
\text { abandonar atividade } \\
\text { em associações } \\
\text { Trabalhar menos à } \\
\text { noite } \\
\text { Períodos de repouso } \\
\text { mais numerosos e mais } \\
\text { longos: menos saídas } \\
\text { familiares } \\
\text { Toma } \\
\text { medicamentos } \\
\text { analgésicos } \\
\text { Redistribuição das } \\
\text { atividades domésticas } \\
\text { com o cônjuge } \\
\text { Cessação precoce da } \\
\text { atividade }\end{array}$ \\
\hline
\end{tabular}




\begin{tabular}{|c|c|c|c|}
\hline $\begin{array}{l}\text { Elementar } \\
\text { Primeiro } \\
\text { grau } \\
\text { (Homens e } \\
\text { Mulheres) }\end{array}$ & $\begin{array}{l}\text { Fadiga mais acentuada } \\
\text { jornada de trabalho (física e } \\
\text { psicológica) } \\
\text { Sentimento de redução dos } \\
\text { recursos para enfrentar a } \\
\text { atividade e os alunos mais } \\
\text { difíceis } \\
\text { Maior intolerância à intrusão } \\
\text { do trabalho na vida privada } \\
\text { Maior sensibilidade ao ruído } \\
\text { Maior tensão nervosa, menos } \\
\text { paciência } \\
\text { Maior dificuldade nos } \\
\text { exercícios desportivos } \\
\text { Dificuldades de recuperação } \\
\text { Problemas de saúde } \\
\text { relacionados com a altura das } \\
\text { mesas de trabalho e de } \\
\text { escrever no quadro (cirurgia } \\
\text { a um ombro e uma costela) } \\
\text { Menos entusiasmo, menos } \\
\text { energia para realizar a } \\
\text { atividade a } \\
\text { Cada vez mais dissonâncias / } \\
\text { evolução da profissão } \\
\text { Sentimento de que certos pais } \\
\text { reparam na idade; impacto } \\
\text { parte positivo (sinal de } \\
\text { experiência), parte negativo } \\
\text { (falta de dinamismo) } \\
\text { Necessidade de gerir a visão } \\
\text { dos alunos sobre } \\
\text { problemática a } \\
\text { envelhecimento na atividade } \\
\text { (avô-avó) }\end{array}$ & $\begin{array}{l}\text { Para evitar baixar-se nas } \\
\text { mesas de trabalho, } \\
\text { convencer os alunos a vir à } \\
\text { secretária } \\
\text { Menos saídas escolares / } \\
\text { menos envolvimento nas } \\
\text { atividades nas saídas } \\
\text { Desejo de não mudar de } \\
\text { nível escolar, sobretudo } \\
\text { para o pré-escolar, mais } \\
\text { exigente do ponto de vista } \\
\text { físico } \\
\text { Aceitar funções de direção } \\
\text { para ter menos funções de } \\
\text { ensino } \\
\text { No desporto, fazer fazer os } \\
\text { alunos }\end{array}$ & $\begin{array}{l}\text { Trabalhar menos ou } \\
\text { nada à noite } \\
\text { Prática de atividades } \\
\text { recuperadoras, } \\
\text { abandonar atividade } \\
\text { em associações } \\
\end{array}$ \\
\hline
\end{tabular}




\begin{tabular}{|c|c|c|c|}
\hline $\begin{array}{l}\text { Secundário } \\
\text { Segundo } \\
\text { grau } \\
\text { (Homens e } \\
\text { Mulheres) }\end{array}$ & $\begin{array}{l}\text { Fadiga / esgotamento } \\
\text { Maior sensibilidade ao ruido } \\
\text { Menos paciência / } \\
\text { comportamento dos alunos, o } \\
\text { seu não envolvimento na aula } \\
\text { Problemas de saúde } \\
\text { geradores de dores na } \\
\text { atividade (profs de EFD) } \\
\text { Sentimento de ter menos } \\
\text { recursos para enfrentar a } \\
\text { atividade e os aluno cada vez } \\
\text { mais difíceis } \\
\text { Sentimento de diferença } \\
\text { geracional que se cruza e } \\
\text { perturba a atividade: menor } \\
\text { controlo } \\
\text { Cada vez mais dissonâncias / } \\
\text { evolução da profissão } \\
\text { Maior intolerância à } \\
\text { interferência do trabalho na } \\
\text { vida privada }\end{array}$ & $\begin{array}{l}\text { Recusa em fazer horas } \\
\text { extraordinárias, escolhendo } \\
\text { horários a tempo parcial } \\
\text { para as poder recusar } \\
\text { Renúncia ao cargo de } \\
\text { diretor de turma } \\
\text { Redirecionar os projetos das } \\
\text { turmas em que lecionam } \\
\text { Negociação calma na sala de } \\
\text { aula com os alunos } \\
\text { perturbadores } \\
\text { Solicitar ter menos horas de } \\
\text { aulas por dia, espaçando-as } \\
\text { pela semana } \\
\text { Limitação do numero de } \\
\text { níveis de turmas por ano } \\
\text { Menos participação nos } \\
\text { projetos interdisciplinares } \\
\text { Passagem para tempo } \\
\text { parcial }\end{array}$ & $\begin{array}{l}\text { Parar com atividades } \\
\text { de ensino fora do } \\
\text { estabelecimento } \\
\text { escolar } \\
\text { Períodos de repouso } \\
\text { mais numerosos e mais } \\
\text { longos: menos saídas } \\
\text { familiares } \\
\text { Trabalhar menos à } \\
\text { noite } \\
\text { Redistribuição das } \\
\text { atividades domésticas } \\
\text { com o cônjuge } \\
\text { Prática de atividades } \\
\text { recuperadoras, } \\
\text { abandonar atividade } \\
\text { em associações }\end{array}$ \\
\hline
\end{tabular}

57 Parece que a problemática do fim de carreira será mais aguda nos professores/as do primeiro grau, especialmente na Pré-Escola, devido à impossibilidade de evitar, mesmo que temporariamente, o face a face com os alunos sob a sua responsabilidade 24 por semana e durante todo o dia. A dependência dos jovens alunos também é um fator de envolvimento físico na atividade podendo criar um desgaste prematuro do corpo. Isto ajuda a explicar que, apesar de alterações recentes terem mudado a idade de reforma para os 60 anos, certos/as professores/as estão a retirar-se por volta dos 55 ou 57 anos, apesar de seu amor à profissão e da penalização financeira que tal decisão implica.

\subsection{Uma atividade de ensino mais custosa em fim de carreira}

58 A partir dos 50 anos, alguns anos antes para alguns, os professores tendem a perceber um aumento das dificuldades sentidas no exercício da sua profissão, independentemente do grau escolar; isto é, um aumento do custo do trabalho e a sensação de ter que mobilizar mais recursos do que antes para aguentar as exigências profissionais, que não param de aumentar.

Nesta profissão, que os professores, na maioria dos casos, praticaram ao longo de toda a sua carreira, encontra-se a ideia desenvolvida por alguns autores de que a idade, sinónimo de uso prolongado de seu corpo e de desgaste de si (Lapeyre \& Thébaud, 2006), pode estar associada a fenómenos de esgotamento profissional (burnout) no ensino secundário (Burke, Greenglass \& Schwarze, 1996), de vulnerabilidade da saúde especificamente em primeiro grau (Cau-Bareille, 2009) e de dificuldades "em aguentar" até à reforma em todos os graus. Os problemas de saúde, especialmente no primeiro grau, estão mais presentes. Este termo desgaste, no sentido mais amplo, refere-se à ideia de um comprometimento da saúde global, não se reduzindo necessariamente aos 
danos físicos, mas combinando os efeitos do avanço da idade e os vestígios de toda a vida profissional. Ora, "A maioria dos problemas de saúde contribuem para o desejo de "sair mais cedo": é o caso das patologias, mas de forma mais significativa, dos problemas difusos como "ficar cansado rapidamente"' explica Molinié (2012, p. 322, tradução livre); o que é o caso de muitos dos professores que conhecemos. Com a idade, o corpo regista as mudanças físicas e psicológicas que necessitam de ajustes no local de trabalho; medidas que são inexistentes na Educação Nacional, devido à ausência de medicina do trabalho e de uma reflexão interna sobre as condições de trabalho para o desenvolvimento de ações preventivas.

\subsection{Um desgaste do corpo e um desgaste psíquico acentuados por um desgaste organizacional} Thebaud (2006, p 8, tradução livre) com seniores do sector hospitalar e da indústria aeronáutica: "o desgaste organizacional é produzido por uma forma de organização que se usa, que se rigidifica, que carece de flexibilidade, que está em crise. 0 desenvolvimento de fenómenos de desgaste organizacional relaciona-se com a difusão de novas formas de organização do trabalho nas últimas duas décadas".

61 As mudanças nas profissões docentes inscrevem-se numa lógica política de alinhamento do funcionamento das instituições da função pública com o funcionamento das empresas privadas. Na verdade, com as novas formas de gestão da Educação Nacional, chegaram os imperativos da rentabilidade, da gestão pelos números através de avaliações que não só perturbam o conteúdo do trabalho, os objetivos pedagógicos e o sentido da profissão, mas também o levar pouco em conta as competências construídas ao longo de anos de experiência. Os professores em fim de carreira encontram-se cada vez mais em dissonância entre, por um lado, o que eles querem fazer na sua atividade e que parece relevante à luz do seu conhecimento da profissão, dos alunos e das suas dificuldades e, por outro, as injunções da hierarquia que muitas vezes não entendem, às quais não se querem necessariamente juntar, arriscando mesmo a "desobedecer", nas suas palavras (Cau-Bareille, 2012) ou a recusar inspeções (Cau-Bareille, 2009). Os professores sentem-se negados nas suas competências e forçados a concretizar reformas que vão contra a sua ética profissional. Ora, de acordo com Molinié (2012, p. 332, tradução livre), "o sentimento de não ser reconhecido pelo seu valor justo é acompanhado por um aumento da probabilidade de que os problemas de saúde sejam vistos como indesejáveis na atividade de trabalho". Assim, como já vimos, é o desejo de alguns "abandonar o navio o mais rápido possível, antes que o barco afunde" ( $\mathrm{H}, 1^{\circ}$ grau, 52 anos).

Podemos ver claramente que as dificuldades dos fins de carreira não estão apenas relacionadas com o processo de envelhecimento, mas também com o contexto de trabalho, as condições de atividade, as mudanças que afetam as profissões. Refletir nos fins de carreira supõe, pois, pôr no centro da reflexão "o sistema de trabalho" na sua totalidade.

63 Os professores/as são ativos na gestão dos seus fins de carreira: eles desenvolvem estratégias alternativas contra causas de sofrimento ou de dificuldades, de compensação para ter que concretizar uma tarefa apesar de tudo (Molinié, 2012); demos vários exemplos. Estes desenvolvimentos serão a fonte de modos de regulação 
que assumem formas muito diferentes, dependendo do nível de ensino em que atuam. De facto, se as formas de organização do trabalho não são semelhantes, as possibilidades de regular as dificuldades vividas são diferentes, como já vimos.

\subsection{Os limites das regulações do modo de vida}

64 Mas as regulações podem encontrar os seus limites: "Eu estou preocupada. E eu não posso melhorar a minha vida todos os dias: eu estou ao máximo a fazer tudo o que posso para não me cansar, eu pus em prática tudo o que eu poderia fazer" (F, $1^{\circ}$ grau, 52 anos). Vemos aqui, que da satisfação encontrada na concretização de regulações depende o sentimento de eficácia profissional em torno do qual se elabora a decisão de deixar a atividade prematuramente. Conforme destacam Almudever, Croity-Belz, Hajjar e Fraccaroli (2006, p. 152, tradução livre), "os indivíduos não podem desenvolver ou manter as razões de agir e de perseverar quando confrontados com dificuldades, se eles não acreditam que podem conseguir os resultados que desejam através das suas ações". Deste ponto de vista, os nossos resultados corroboram os resultados destes pesquisadores, segundo os quais "há um grau mediano de interdependência entre as áreas da vida que corresponde a um sentimento de eficácia pessoal geral satisfatório" (op. cit., p. 156, tradução livre). Se, para aguentar as exigências de trabalho, os assalariados são constrangidos a mais e mais regulações fora da esfera do trabalho, "a perturbação profissional transmite então os seus efeitos negativos para além da esfera profissional para alcançar o bem-estar psicológico global dos indivíduos" (op. cit., p. 164, tradução livre). Podemos ver claramente a passagem de "sentir-se capaz de trabalhar" até à reforma até "aguentar até à reforma, numa profissão onde a pessoa se reconhece cada vez menos". Daqui surgem as preocupações com os últimos anos de atividade profissional.

As saídas antecipadas advêm, pois, frequentemente, de deliberações difíceis. Trata-se mais de soluções de último recurso para preservar a sua saúde do que uma estratégia de saída para investir em outras atividades, especialmente entre as mulheres. Os professores colocam no centro da decisão os aspetos subjetivos da saúde, do bem-estar no trabalho, o "sentido do trabalho". E é esta tensão entre experiência e avanço da idade ao longo do tempo, este equilíbrio almejado no trabalho e nas suas vidas pessoais, que estão no coração das escolhas em fim de carreira. Quanto mais os professores se sentem em dificuldades, mais procuram ajustes no trabalho e fora do trabalho; quanto menos esses ajustes resultam, mais o seu desejo de antecipar a saída é notório. Para retomar Curie, referindo-se a Malrieu (1979 in 2002, p. 30, tradução livre): "O sujeito regula os seus comportamentos numa área da vida através do sentido que lhes dá em outras áreas da vida". Segundo o autor, "o percurso profissional não é redutível nem a forças externas que atuam sobre o indivíduo nem a uma estrutura interna que préexistiria às mutações profissionais, mas vai depender de como o indivíduo combina, numa estratégia pessoal, umas e outras" (op. cit, p. 26, tradução livre). Isto remete para o conceito de "sentimento de eficácia pessoal", desenvolvido por Bandura \& Locke (2003) e retomado por Almudever e colaboradores (2006), que corresponde à avaliação pessoal que uma pessoa faz da sua capacidade para gerir e dar continuidade ao curso de ação necessário. Esta avaliação não está apenas relacionada com as competências a exercer na atividade, mas sim com o sentimento individual que se desenvolve quanto à sua capacidade de lidar com a situação. Assim, o desejo de continuar a trabalhar parte 
de uma avaliação global, que não se limita ao que é vivido somente na esfera profissional, mas incorpora o sentimento de controlo em cada uma das áreas da vida.

\subsection{Situações de desequilíbrios mais pronunciadas nas mulheres?}

As tentativas de equilibrar as esferas da vida são frequentemente bem diferentes entre homens e mulheres. Embora os modelos sociais tenham evoluído, as mulheres hoje investem ainda muito mais na família do que os homens (Cacouault-Bitaud, 2003; Ponthieux \& Schreiber, 2006; Jarty, 2009): as tarefas diárias, cuidar das crianças, dos idosos, são tarefas sempre mais garantidas pelas mulheres do que pelos homens. Isto parece trazer várias consequências, que se articulam e reforçam: um trabalho de articulação das diferentes esferas da vida mais intenso para as mulheres do que para os homens, dificuldades em aguentar todas as esferas e a impressão de estar a "fazer tudo mal" que é geradora de insatisfação a curto e a longo prazo, um sentimento de estar despedaçado, fonte de esgotamento, uma sobrecarga global de trabalho e um alto nível de stress. Estas dificuldades de articulação têm consequências não só sobre a forma como os professores vão viver a sua atividade de trabalho, mas fundamentalmente no seu estilo de vida e na sua saúde a longo prazo. Uma situação que pode pesar ao longo dos anos e criar um fenómeno de desgaste prematuro. Subscrevemos neste ponto de vista as conclusões de Messing e Östlin (2006) de acordo com as quais não se pode compreender a saúde das mulheres associada ao trabalho sem se acrescentar outras estruturas relacionadas aos papéis dos homens e das mulheres e ao trabalho das mulheres no meio familiar. De forma mais ampla, pode-se pensar que o género é uma dimensão importante a ter em conta na análise dos fins de carreira e dos fenómenos de desgaste prematuro.

\section{Pistas de reflexão para criar condições para o bem- estar no fim da carreira?}

67 Tendo em vista estes diferentes elementos, vários tipos de planos podem ser propostos para criar as condições de um "envelhecer bem no trabalho".

\subsection{A gestão do tempo de trabalho}

\subsubsection{O tempo parcial}

A gestão do tempo de trabalho sob a forma de tempo parcial é muitas vezes considerada pelos/as professores/as como um possível contributo para a redução da carga de trabalho, no sentido de melhor gerir a fadiga ligada ao exercício da profissão em fim de carreira, para criar as condições para aguentar com saúde e para "redescobrir o prazer de trabalhar com os alunos". É mais comum nas mulheres do que nos homens que entrevistamos. Trata-se de uma estratégia de preservação para evitar as ruturas, para as antecipar. "Eu comecei a tempo parcial aos 50 anos, porque eu estava esgotada! Eu vi-me num impasse em continuar desta forma. Ter o meu meio tempo permite-me redescobrir o prazer do trabalho. Eu não tenho problemas de saúde. Quando se está esgotado, o prazer não existe! Eu senti que estava a prejudicar a minha atividade de tão cansada que estava, eu não estava a ouvilos, porque eu estava completamente em colapso, mesmo!" (F, $1^{\circ}$ grau, 52 anos). 0 trabalho a tempo parcial é muitas vezes visto como um compromisso aceitável para viver os 
últimos anos de uma profissão que muitos professores/as consideram ser "uma das mais belas profissões do mundo". A possibilidade de trabalhar a tempo parcial também é considerada pelos políticos como condição para a extensão do período de atividade profissional: "A redução do tempo de trabalho em fim de carreira pode ajudar a incentivar os trabalhadores a permanecer no mercado de trabalho, a atrasar a reforma, ou mesmo a acumular trabalho e reforma" (Jolivet, 2003, p.12, tradução livre).

No primeiro grau, se as mulheres, em particular, consideram por vezes esta possibilidade, elas hesitam nessa opção para preservar a qualidade do trabalho, para o bem dos alunos: algumas acreditam que dois meios tempos numa turma pode ser um problema para as crianças, que procuram estabilidade. $O$ problema é diferente para os professores do ensino secundário, que são especialistas da disciplina e não são a única referência dos alunos: aqui, eles vêm o número de aulas em que atuam diminuir. Mas pode-se pensar que, no contexto do prolongamento das carreiras e de um aumento das situações de divórcio, as mulheres hesitam em escolher esta opção, mesmo que sintam a necessidade, devido ao impacto que isso poderia ter sobre a sua remuneração na reforma. Este fenómeno já é percetível nos últimos anos.

\subsubsection{Dar a possibilidade aos seniores de recusar as horas extraordinárias}

70 Uma nova medida de prevenção primária poderia consistir na promulgação de uma lei que proibisse os empregadores de impor horas extraordinárias aos assalariados com mais de 50 anos, ao mesmo tempo, tendo em conta o aumento do custo do trabalho em fim de carreira e como estratégia de prevenção da saúde dos seniores (privilegiar o voluntariado). Encontrámos no nosso estudo dois professores que deixaram a profissão por não poder assumir as horas extraordinárias [9], impostas pelo diretor do estabelecimento por razões de serviço (Cau-Bareille, 2009).

\subsection{Restabelecer as CPA (Cessação Progressiva da Atividade)}

Embora a redução do tempo de trabalho pareça uma ideia interessante para criar as condições de atividade dos seniores, as alterações em matéria de reformas reduzem essas oportunidades. De facto, o artigo 54 da Lei $\mathrm{n}{ }^{\circ}$ 2010-1330, de 9 de Novembro de 2010, sobre a alteração das reformas retira o acesso ao dispositivo CPA, com efeitos desde 1 de Janeiro de 2011, para os assalariados em fim de carreira. A Lei deu a oportunidade de trabalhar a tempo parcial recebendo uma remuneração maior do que a correspondente à duração efetiva do tempo de trabalho (trabalhar $50 \%$ do horário é retribuído a $80 \%$ ); este dispositivo está disponível a partir de 55 anos de idade. Os professores encontram-se, portanto, numa situação paradoxal: as medidas de acompanhamento dos fins de carreira desaparecem, precisamente quando são mais necessárias no contexto do prolongamento das carreiras. Os resultados do nosso estudo questionam, pois, a relevância das medidas legislativas sobre as CPA; medidas que só podem levar a mais absentismo e mais situações de ruturas.

\subsection{Instaurar uma real medicina do trabalho}

Os professores franceses não têm medicina do trabalho: 67 médicos ditos "de prevenção" asseguram todo o território francês, tanto para o pessoal docente como para o técnico que trabalha nos estabelecimentos escolares. Isto significa que os professores não 
beneficiam de um acompanhamento médico regular que possa identificar as pessoas em dificuldade, especialmente para a prevenção (ao longo da carreira, a maioria dos professores tem apenas uma visita ao médico, no momento de entrada na profissão). Por falta de recursos humanos, as consultas médicas ocorrem apenas a pedido dos funcionários, portanto já com queixas, com um tempo de espera de várias semanas. Num fórum sindical FSU em maio de 2011, o Dr. Maitrot (médico de prevenção da Educação Nacional), explicou que "os que têm mais de 50 anos representam 47,5\% das consultas médicas, 56\% dentro de psiquiatria", resultados que corroboram as observações de Papart (2003). A autora aponta ainda problemas de saúde significativos entre professores em fim de carreira, como incapacidades, que aparecem de pouco a pouco, sublinhando a falta de meios para realmente tomar conta desse problema e criar reclassificações.

73 A extensão da atividade profissional exige, portanto, uma maior vigilância médica dos assalariados, para evitar situações de rutura, uma vez que, demasiadas vezes, vivem na solidão, origem de vários casos de suicídios que hoje lamentamos [10].

\subsection{Introduzir os planos seniores ['] ${ }^{1}$ na Educação Nacional}

74 A Educação Nacional aproveita pouco os planos seniores para resolver o problema dos fins de carreira: nenhum recrutamento de seniores, nenhuma ação para melhorar as condições de trabalho nem medidas preventivas, desaparecimento das medidas CPA (Cessação Progressiva da Atividade) que permitiam anteriormente que os funcionários previamente autorizados reduzissem o seu tempo de trabalho, nenhuma implementação de um sistema de tutoria que permita libertar os seniores do seu tempo de ensino. Atualmente, só as entrevistas de segunda carreira [ $\left.{ }^{12}\right]$ são realizadas, mas ainda há muito pouco feito. Dada a atividade dos professores, coloca-se o problema dos postos adequados para as pessoas com grandes dificuldades: adaptados em torno de que critérios? Existem poucos recursos para modificar a atividade de trabalho no face a face com os alunos. Da mesma forma, as oportunidades de planeamento da carreira, pouco numerosas no ensino primário, são altamente dependentes do modo de gestão das escolas e dos diretores, que não são formados nesta problemática do envelhecimento.

Segundo o Dr. Maitrot (citado acima), a medida com maior probabilidade de se generalizar na Educação Nacional é a entrevista da segunda parte da carreira que permite que os professores com dificuldades mudem a sua trajetória profissional. No entanto, desde 2010, o sindicato UNSA relatou que, no caso dos professores, as "segundas carreiras", prometidas na alteração das reformas, chegaram a apenas algumas dezenas de professores: uma gota de água no universo da população considerada. Além disso, no contexto da redução de postos de trabalho do ensino, as restrições têm-se centrado principalmente nos postos ligeiros ou ditos "leves"; daí a escassez de oportunidades de "abrigo" para os assalariados em dificuldade.

Podemos ver aqui um desafio a trabalhar-se mais, fundamentalmente, sobre as condições de trabalho docentes, e não só em fim de carreira, a fim de se antecipar os problemas e a, como diz Obéniche (2011), se empenhar na qualidade dos percursos profissionais. 


\section{Conclusão}

Os resultados da nossa investigação exploratória levantam, por fim, um questionar que vai para além da problemática dos professores. Alterações para prolongar as carreiras e adiar a idade de reforma dificilmente levantam a questão da saúde dos assalariados e do vivido do trabalho. Não se integram na reflexão elementos essenciais, tais como a relação subjetiva no trabalho, a saúde no trabalho, os efeitos do desgaste, que determinam a relação com o trabalho em fim de carreira, podendo provocar as saídas precoces, o absentismo, os problemas de saúde. Zonas de sombra que tornam urgentes as pesquisas sobre os seniores e suas condições de trabalho. De facto, apesar dos incentivos para manter os professores seniores no emprego, os fenómenos de exclusão existem, por iniciativa de empregadores e de assalariados, e os próprios trabalhadores mais velhos podem sentir-se vulneráveis na sua saúde, na sua relação com o trabalho, com o sentido do trabalho.

O nosso estudo fornece evidências que precisam de ser aprofundadas, colocando o problema de "envelhecer bem no trabalho" com uma nuance adicional: envelhece-se a trabalhar da mesma forma, conforme se é homem ou mulher? Embora o ponto de entrada do nosso estudo não tenha sido a problemática do género, esta dimensão emergiu como tão rica, interessante e diferenciada como podendo revelar o vivido do trabalho dos professores/as. Os nossos primeiros resultados indicam um efeito de desgaste prematuro nas mulheres professoras ligado quer às condições de trabalho (elas que estão sobre representadas nos níveis em que as crianças são mais novas, mais dependentes dos adultos e mais solicitantes física, mental e emocionalmente), à difusão do trabalho fora do trabalho numa profissão onde a porosidade entre as esferas da vida é importante, a um trabalho de articulação das esferas de vida que parece bastante complicado ao contrário das representações que podem existir sobre este tipo de profissão. Esta tem um impacto sobre a sua saúde, sobre o vivido do trabalho, sobre as estratégias de gestão dos últimos anos de atividade profissional, tanto no campo do trabalho como fora dele. Esta abordagem permite ir um pouco mais longe do que os trabalhos de Hansez e colaboradores (2005) para compreender os desejos de reforma antecipada. Este estudo exploratório permitiu sobretudo compreender que não podemos pensar sobre o problema do fim de carreira sem integrar a dimensão do género.

79 Deste ponto de vista, percebemos que há um verdadeiro vazio em torno das condições para "envelhecer bem no trabalho". Os acordos de emprego dos seniores, a prevenção das situações de penosidade, serão suficientes para criar as condições para a manutenção da atividade até a data especificada pelas políticas? Quais são as condições de um trabalho em fim de carreira facilitadoras de eficiência, de desenvolvimento, garantindo a saúde física, mental, psicológica, dos assalariados, tanto no trabalho como em outras áreas da vida? Fundamentalmente, coloca-se a questão da sustentabilidade das condições de trabalho ao longo do tempo. Isto não pode ser feito sem uma análise detalhada das formas de penosidade do trabalho específicas de cada profissão; penosidade, não só do ponto de vista físico (é a única levada em conta nas políticas atuais), mas também mental e psíquica. Parece ser essencial nas profissões de relações de serviço, onde as formas de sofrimento muitas vezes permanecem invisíveis.

80 A problemática do emprego dos seniores leva-nos, pois, a pensar de outra forma o trabalho: pensar o emprego "durável", "o trabalho sustentável" (Jolivet, 2011, p.7, 
tradução livre), viável em todas as idades da vida, para as mulheres como para os homens; um desafio urgente a empreender, para o bem-estar dos assalariados.

\section{BIBLIOGRAFIA}

Almudever, B., Croity-Belz, S., Hajjar, V., \& Fraccaroli, F. (2006). Conditions for efficiency of the self-efficacy beliefs in regulating professional disruption: dynamics of the system of Activities. Psychologie du travail et des organisations, 12, 151-166.

Bandura, A. \& Locke, E.A. (2003). Negative self-efficacy and goals effects revisited. Journal of Applied Psychology, 88, 87-99.

Bauer, J., Stamm A., Virnich, K., Wissing, K., Müller, U., Wirsching M., \& Schaarschmidt, U. (2006). Correlation between burnout syndrome and psychological and psychosomatic symptoms among teachers. International Archives of Occupational and Environmental Health, 79, 199-204.

Bieri, T. (2002). Die berufliche Situation aus der Sicht der Lehrperson. Zufriedenheit, Belastung, Wohlbefinden und Kündigungen im Lehrberuf. Dissertation, Universität Tübingen.

Burke, R., Greenglass, E., \& Schwarze, R. (1996). Predicting teacher burnout over time; effects of work stress, social support and self-doubts on burnout and its consequences. Anxiety, stress and coping: an International Journal, 9 (3), 261-275.

Cacouault-Bitaud, M. (2003). La sociologie de l'éducation et les enseignants : cherchez la femme ... In J. Laufer, C. Marry, \& M. Maruani (Eds.) Le travail du genre (pp. 163-180). Paris : La Découverte/ Mage.

Cau-Bareille, D. (2009). Vécu du travail et santé des enseignants en fin de carrière : une approche ergonomique. Centre d'Études de l'Emploi, 56, 1-65. Retirado de http://www.cee-recherche.fr/fr/ rapports/56-vecu-travail-sante-enseignants-carriere-ergonomique.pdf

Cau-Bareille, D. (2012). "Obey", "disobey" or "tinker with" reforms to the system: a subject for French teacher trade unions to work on. Work, 41, 5218-5227. DOI: 10.3233/WOR-2012-0812-5218.

Comité syndical européen de l'éducation (2011). Stress lié au travail des enseignant(e)s : analyse comparative et évaluation de l'impact des risques psychosociaux sur les enseignant(e)s sur leur lieu de travail dans l'UE. Bruxelle. Etuce / CSEE, 26. Retirado de http://etuce.homestead.com/ Publications2011

Curie, J. (2002). Parcours professionnels et interdépendances des domaines de vie. Éducation Permanente, 150, 23-32.

Day, C., Stobart, G., Sammons, P., Kington, A., Gu, Q., Smees, R., \& Mutjabe, T. (2006). Variations in teachers's work, lives and effectiveness (VITAE). Research Report 743. London: Department for Education and Skills.

Faverge, J-M. (1979-80). Le travail en tant qu'activité de récupération. Bulletin de Psychologie, 33 (344), 203-206. 
Faverge, J-M., Olivier, M., Delahaut, J., Stephaneck, P., \& Falmagne, J.C. (1970). L'ergonomie des processus industriels. Études de psychologie sociale et industrielle. Université Libre de Bruxelles. Retirado de gouv.fr/file/194/13/9/dossier194_123139.pdf

González, R. \& Weill-Fassina, A. (2005). Modalités de régulation du processus de travail dans les activités de service en crèche. Activités, 2 (2), 2-23. Retirado de http://www.activites.org/v2n2/ Gonzales.pdf

Guglielmi, R. S. \& Tatrow, K. (1998). Occupational Stress, Burnout, and Health in Teachers: a methodological and Theoretical analysis. Review of Educational Research, 68 (1), 61-99.

Gursel, M., Murat Sunbul, A., \& Sari H. (2002). An analysis of burnout and job satisfaction between Turkish headteachers and teachers. European Journal of Psychology of Education, 17 (1), 35-45.

Hansez, I., Bertrand, F., De Keyser, V. et Pérée, F. (2005). Fin de carrière des enseignants : vers une explication du stress et des retraites prématurées. Le travail humain, 68 (3). 193-223.

Jaoul, G., Kovess, V., \& FSP-MGEN (2006). Le burnout dans la profession enseignante. Annales Médico Psychologiques, 162, 26-35. DOI:10.1016/j.amp.2003.03.002

Jarty, J. (2009). Les usages de la flexibilité temporelle chez les enseignantes du secondaire, Temporalités, 9. Retirado de http://temporalites.revues.org/index1057.html

Jolivet, A. (2003). Partir en retraite plut tôt ou plus tard : quelles implications d'une ouverture des marges de choix individuel ? Revue de l'IRES, 43, (3), 1-21.

Jolivet A. \& Lee S. (2004). Employment conditions in an ageing world: Meeting the working time challenge. Conditions of work and employment series, 9, 1-38. Retirado de www.ilo.org/public/ english/protection/condtrav/time/time_publ.htm

Jolivet, A. (2011). Allongement de la vie professionnelle : comment agir ? Revue Travail et changement, 337. Retirado de http://www.pdl.aract.fr/telechargement/Travailetchangement/ Travail_et_Changement_Mai_Juin_2011.pdf

Lantheaume, F. \& Hélou, C. (2008). La souffrance des enseignants : une sociologie pragmatique du travail enseignant. Paris : Presses universitaires de France.

Lapeyre, N. \& Thébaud C. (2006). Les facteurs d'usure au travail chez les seniors et leurs effets selon le sexe. Un exemple dans le secteur hospitalier et l'industrie aéronautique. Rapport de recherche Equal : étude action sur la santé au travail, 1-75.

Leplat, J. (2000). L'analyse psychologique de l'activité en ergonomie : aperçu sur son évolution, ses modèles et ses méthodes. Toulouse: Edition Octarès.

Messing, K. \& Östlin, P. (2006). Gender Equality, work and health: A Review of the Evidence. Geneva: World Health Organisation.

Molinié, A. F. (2005). Se sentir capable de rester dans son emploi jusqu'à la retraite ? PISTES, 7 (1), 1-25. Retirado de http://pistes.revues.org/3254\#tocto3n9

Molinié, A. F. (2012). Facettes de la pénibilité, prisme du genre : une analyse de l'enquête santé et vie professionnelle après 50 ans. In A. F. Molinié, C. Gaudart, \& V. Pueyo (Eds.). La vie professionnelle : âge, expérience et santé à l'épreuve des conditions de travail (pp.315-342). Toulouse : Editions Octarès.

Obéniche, J.B. (2011). Allongement de la vie professionnelle : comment agir ? Revue Travail et changement, 337. Retirado de http://www.pdl.aract.fr/telechargement/Travailetchangement/ Travail_et_Changement_Mai_Juin_2011.pdf 
Papart, J. P. (2003). La santé des enseignants et des éducateurs de l'enseignement primaire Rapport à l'organisation du travail. Genève : Actions en santé publique. Retirado de ftp:// ftp.geneve.ch/primaire/rapport-papart.pdf

Pillay, H., Goddard, R. \& Wilss, L. (2005). Well-being, burnout and competence: implications for teachers. Australian Journal of Teacher Education, 30 (2), 22-33.

Ponthieux, S. \& Schreiber, A (2006). Dans les couples de salariés, la répartition du travail domestique reste inégale. Données sociales, La Société Française, 43-51. Retirado de www.insee.fr/fr/ffc/docs_ffc/donsoc06d.pdf

Schaarschmidt, U. (2004) Halbtagsjobber? Psychische Gesundheit im Lehrerberuf. Analyse eines veränderungsbedürftigen Zustandes. Weinheim: Beltz.

Vandenberghe, R. \& Huberman, M. (1999). Understanding and Preventing Teacher Burnout: a sourcebook of International Research and Practice. United States of America: Cambridge University Press.

Article de presse du SNES / FSU du $1^{\circ}$ novembre 2010 : La cessation progressive d'activité supprimée - http://www.reims.snes.edu/spip/spip.php?article1690

Article de presse de l'UNSA du 12 septembre 2010 : Retraites : une nouvelle provocation contre les fonctionnaires

http://www.unsa-education.org/modules.php?name=News\&file=print\&sid=1617

Repères et références statistiques sur les enseignements, la formation et la recherche. Statistiques - publications annuelles - Édition 2013

http://www.education.gouv.fr/cid57096/reperes-et-references-statistiques.html

\section{NOTAS}

1. Os professores do ensino secundário têm 18 horas de aulas por semana, no mínimo, para garantir com os alunos, quando são certificados (quando obtiveram o CAPES [certificado de aptidão de professor para o ensino de segundo grau]).

2. Agregados são os professores que passaram um concurso de docência de nível superior, muito seletivo. Isto dá-lhes o direito de ensinar até 14 horas por semana; eles lecionam com mais frequência no ensino secundário.

3. Na lei de 2010 (artigo L 4121-3-1), a penosidade está associada, em primeiro lugar com a exposição a um ou mais fatores de riscos ocupacionais suscetíveis de deixar traços duráveis, identificáveis e irreversíveis, e por outro lado, estes mesmos fatores de risco, determinado por decreto, relacionam-se com constrangimentos físicos marcados, um ambiente agressivo ou certos ritmos de trabalho.

A Lei de 9 de Novembro de 2010 sobre a reforma das pensões, afirma que os fatores de risco ocupacionais serão determinados por decreto. É um decreto de 30 de Março de 2011 e que veio listar 10 fatores de risco ocupacionais (L. 4121-3-1):

$1^{\circ}$ Os constrangimentos físicos marcados são a movimentação manual de cargas definidas no artigo R. 4541-2; as posturas dolorosas definidas como posições forçadas das articulações; as vibrações mecânicas mencionadas no artigo R. 4441-1;

$2^{\circ}$ Sob o título de ambiente físico agressivo, estão os agentes químicos perigosos referidos nos artigos R. 4412-3 e R. 4412-60, incluindo poeiras e fumos; as atividades em meio hiperbárico definidas no artigo R. 4461-1; temperaturas extremas; o ruído referido no artigo R. 4431-1; 
3ำ Sob a designação de certos ritmos de trabalho: trabalho noturno nas condições previstas nos artigos L. 3122-29 a 3122-31 L.; trabalho contínuo por turnos; trabalho repetitivo caracterizado pela repetição do mesmo gesto, numa cadência intensa, imposta ou não pela deslocação automática de uma peça ou por remuneração à peça, com um tempo de ciclo definido.

4. Relatório anual sobre o estado da função pública - Factos e Números 2007-2008, p.540.

5. Em ergonomia, as regulações designam processos implementados pelos operadores para construir compromissos entre constrangimentos antagonistas (Faverge, Olivier, Delahaut, Stephaneck, \& Falmagne, 1970; Faverge, 1979-1980). São reações do sujeito a perturbações e destinam-se a compensar reconstruindo o equilíbrio do sistema de atividades. Geralmente manifestam-se por modificações dos modos operatórios no que restar dos espaços de tolerância do sistema. São frequentemente os ajustes, adaptações, desvios, a transformação de procedimentos, muitas vezes dependentes das margens de manobra nas quais se enquadra a atividade. Podemos reinterpretá-las a nível organizacional como estratégias subentendidas por reelaborações mais ou menos implícitas das regras (González \& Weill-Fassina, 2005).

6. Zonas de educação prioritária são áreas em que estão localizadas as escolas com recursos adicionais para lidar com as dificuldades de ordem escolar e social (bairros difíceis).

7. Classes Verdes: aulas realocadas por alguns dias num lugar diferente: aulas na neve, no mar. A turma é normalmente alojada durante uma semana num local aprovado pela Educação Nacional e Juventude e Desporto. As crianças descobrem outras formas de aprendizagem: as aprendizagens escolares misturam-se com a descoberta do meio ambiente e das práticas desportivas.

8. Nas escolas secundárias, os professores são especialistas na sua disciplina. Eles dão 18 horas de aulas quando são certificados (quando obtiveram o CAPES) ou 14 horas, se eles são agregados (que passaram por um concurso suplementar de agregação, o que lhes permite ter um diploma superior).

9. Dependendo das necessidades do serviço e do método de gestão das escolas, o diretor da escola pode exigir aos professores que realizem pelo menos uma hora de trabalho extraordinário.

10. A taxa de suicídio entre os professores é de 39/100 000 por ano, segundo o INSERM (2002); portanto, em teoria, 331 professores são afetados a cada ano, quase uma por dia! "Sem dúvida que muitos mais tentam fazê-lo, mas esses dados não são filtrados, porque em todos os casos, a Educação Nacional desassocia o ato de qualquer situação de trabalho que lhe possa dar origem", adverte a associação Aide aux Profs. http://www.aideauxprofs.org/index.asp? affiche=News_display.asp\&rub=Souffrir_d_enseigner\&ArticleID=2964

11. O Estado francês implementou em 2006 o plano nacional de ação concertada para o emprego dos seniores, com três eixos: 1 - melhorar as condições de trabalho e de prevenção da penosidade, 2 - o planeamento dos fins de carreira, 3 - a transição entre atividade e reforma. Mais ofensiva, a lei de financiamento da Segurança Social de 17 de Dezembro 2008, incitou fortemente de seguida os setores e empresas ou grupos de empresas que empreguem pelo menos 50 assalariados para assinar acordos ou a elaborar planos de ação para encorajar o emprego dos assalariados mais velhos. Devem prever um objetivo de manutenção do emprego dos assalariados com idade superior a 55 anos e/ou um objetivo de contratação de assalariados com mais de 50 anos, bem como medidas para ajudar a atingir esses objetivos globais sob pelo menos três das seguintes seis áreas de ação: 1 - recrutamento de assalariados mais velhos na empresa - 2 antecipação da evolução das carreiras profissionais, 3 - melhoria das condições de trabalho e prevenção de situações de penosidade - 4 - desenvolvimento de competências e qualificações, e acesso à formação - 5- planeamento dos fins de carreira e de transição entre o trabalho e a reforma - 6 transmissão de conhecimentos e de competências e desenvolvimento da tutoria.

A partir de 1 Janeiro de 2010, isto tornou-se uma obrigação. Caso contrário, as empresas ou instituições devem pagar uma contribuição equivalente a $1 \%$ da sua massa salarial.

12. A entrevista de segunda parte da carreira é um momento privilegiado que permite que o assalariado e a empresa preparem e considerem a segunda parte da vida profissional. Permite 
fazer um inventário das suas experiências profissionais anteriores e refletir sobre a direção que se quer levar, no futuro, seja através da mobilidade, aumento de responsabilidades, aquisição de competências complementares, de planeamento das condições de trabalho. Pretende-se evitar as formas de discriminação em relação à população sénior.

\section{RESUMOS}

Este artigo apresenta os resultados de uma pesquisa exploratória sobre os fins de carreiras de professores do primeiro e segundo grau em França. Perante as medidas colocadas em prática pelo governo para prolongar as carreiras, têm-se verificado muitas saídas antecipadas para a reforma nesta profissão. Por meio de entrevistas desenvolvidas com professores quinquagenários do primeiro e segundo ciclo, do sexo feminino e masculino, aprofundadas e centradas na atividade de trabalho, nas estratégias implementadas no trabalho diário e no seu impacto sobre a vida fora do trabalho, procurou-se compreender as razões para estas saídas, para as dificuldades encontradas em fim de carreira. O nosso objetivo é de apreender o duplo problema do envelhecimento no trabalho e pelo trabalho, tendo em conta tanto a problemática do envelhecimento como os problemas de desgaste profissional. As entrevistas revelaram que à medida que os professores avançam na idade, aumenta o custo humano do trabalho, apesar da experiência adquirida ao longo dos anos. Os problemas de saúde aumentam, a fadiga relacionada com a atividade acentua-se, as necessidades de recuperação são maiores; a sensibilidade aos constrangimentos no trabalho aumenta. O sentimento de eficácia pessoal diminuiu, gerando preocupações sobre a capacidade de "aguentar até à reforma". Esta situação força mais e mais regulações, tanto no âmbito do trabalho como na esfera privada, por vezes, com uma redução do tempo de trabalho, e, em casos extremos, com saídas precoces. Com base nos resultados, propomos pistas de reflexão em torno de condições de trabalho conducentes à manutenção no ativo dos professores quinquagenários (seniores). Apresentamos uma abordagem definida sob o prisma do género.

En este artículo se presentan los resultados de una investigación exploratoria sobre los finales de carrera de profesores de enseñanza primaria / elemental y secundaria en Francia. Desde que el gobierno ha puesto en marcha medidas para alargar las carreras, se han producido muchas jubilaciones anticipadas en esta profesión. Mediante entrevistas detalladas con profesores quincuagenarios del primer y segundo ciclos de enseñanza, hombres y mujeres, enfocadas en la actividad de trabajo, en las estrategias puestas en marcha en el trabajo diario y su impacto en la vida fuera del trabajo, se buscó entender las razones de estas jubilaciones anticipadas y las dificultades encontradas al final de la carrera. Nuestro propósito es entender el doble problema del envejecimiento en y por el trabajo, tanto la problemática del envejecimiento como los problemas del desgate profesional. Las entrevistas revelaron que a medida que los profesores se hacen mayores aumenta el coste humano del trabajo, a pesar de la experiencia adquirida a lo largo de los años. Los problemas de salud aumentan, la fatiga asociada a la actividad se acentúa, las necesidades de recuperación son más grandes; la sensibilidad a los obstáculos en el trabajo crece. El sentimiento de eficacia personal disminuye, generando preocupaciones sobre la capacidad de "aguantar hasta la jubilación". Esto ha conducido mayores regulaciones, tanto en el ámbito del trabajo como en la esfera privada, a veces, con una reducción del tiempo de trabajo, en casos extremos, con jubilaciones anticipadas. Sobre la base de los resultados, se proponen 
elementos de reflexión pistas de reflexión en torno a condiciones de trabajo que favorezcan el mantenimiento de la vida activa de los trabajadores mayores. Se presenta un enfoque definido bajo la perspectiva de género.

Cet article présente les résultats d'une recherche exploratoire portant sur les fins de carrière des enseignants du premier et du second degré en France. Alors que le gouvernement a mis en place des mesures pour allonger les carrières, on observe de nombreux départs précoces à la retraite dans cette profession. Par le biais d'entretiens approfondis menés auprès d'enseignants quinquagénaires du premier et second cycle, femmes et hommes, centrés sur l'activité de travail, les stratégies mises en œuvre au quotidien dans le travail, son impact sur la vie hors travail, nous avons cherché à comprendre les raisons de ces départs, les difficultés rencontrées en fin de carrière. Notre objectif était d'appréhender la double problématique du vieillir au travail et vieillir par le travail, en tenant à la fois la problématique du vieillissement et les problèmes d'usure professionnelle. Les entretiens ont révélé que, plus les enseignants avancent en âge, plus le coût humain du travail augmente en dépit de l'expérience acquise au fil de l'âge. Les problèmes de santé s'accroissent, la fatigue liée à l'activité s'accentue, les besoins de récupération sont plus importants ; la sensibilité aux contraintes des situations de travail augmente. Le sentiment d'efficacité personnelle diminue, générant des inquiétudes sur la capacité à "tenir jusqu'en fin de carrière". Cela contraint à de plus en plus de régulations à la fois dans le champ du travail comme dans la sphère privée, parfois à une réduction du temps de travail, dans les cas extrêmes à des départs précoces. Sur la base de ces résultats, nous proposerons des pistes de réflexion autour des conditions de travail favorables au maintien en activité des seniors. Nous en venons à envisager une approche davantage définie au prisme du genre.

This paper presents the results of an exploratory research focused on the career of primary and secondary school teachers as they approach retirement in France. While the government implemented measures to lengthen careers, it is observed that many teachers retire before the retirement age set for this profession. Through in-depth interviews with women and men in their fifties, focusing on the work activity, the strategies implemented in the daily work and their impact on their private life, we sought to understand the reasons for the early retirement and the difficulties encountered at the end of the career. The objective was to study the dual problem of ageing at work and ageing because of the work, so both the ageing issue and the problems related to burnout. The interviews revealed that the more the teachers advance in age, the more the human cost of the work increases, despite the experience acquired in the meantime. Health problems increase, the fatigue related to the activity becomes more noticeable, the need for recovery is more important; the sensitivity to the constraints of the working situations increases. Their feeling of personal efficiency decreases, generating concerns on their ability to "hold on until the end of the career". It forces them to more and more regulative strategies at the same time at work and in their private life. Sometimes, it consists in a reduction of working hours or, in the ultimate situations, in early departures. Based on these results, we propose avenues of reflection about working conditions which could help preventing older workers from leaving their jobs. The approach we present is defined according to the gender lens.

\section{ÍNDICE}

Palabras claves: enseñanza, mayores, final de carrera, ergonomía

Mots-clés: enseignement, seniors, fins de carrière, ergonomie

Keywords: teaching, seniors, career endings, ergonomics

Palavras-chave: ensino, fins de carreira, ergonomia 
AUTOR

DOMINIQUE CAU-BAREILLE

Université Lyon 2, IETL, 86, rue Pasteur, 69007 Lyonm France

dominique.cau-bareille@univ-lyon2.fr 